\title{
Retention and multiphase transformation of selenium oxyanions during the formation of magnetite via iron(II) hydroxide and green rust \\ Dol:
}

10.1039/C8DT01799A

\section{Document Version \\ Accepted author manuscript}

Link to publication record in Manchester Research Explorer

Citation for published version (APA):

Börsig, N., Scheinost, A., Shaw, S., Schild, D., \& Neumann, T. (2018). Retention and multiphase transformation of selenium oxyanions during the formation of magnetite via iron(II) hydroxide and green rust. Dalton Transactions. https://doi.org/10.1039/C8DT01799A

\section{Published in:}

Dalton Transactions

\section{Citing this paper}

Please note that where the full-text provided on Manchester Research Explorer is the Author Accepted Manuscript or Proof version this may differ from the final Published version. If citing, it is advised that you check and use the publisher's definitive version.

\section{General rights}

Copyright and moral rights for the publications made accessible in the Research Explorer are retained by the authors and/or other copyright owners and it is a condition of accessing publications that users recognise and abide by the legal requirements associated with these rights.

\section{Takedown policy}

If you believe that this document breaches copyright please refer to the University of Manchester's Takedown Procedures [http://man.ac.uk/04Y6Bo] or contact uml.scholarlycommunications@manchester.ac.uk providing relevant details, so we can investigate your claim.

\section{OPEN ACCESS}




\section{Retention and multiphase transformation of selenium oxyanions during the formation of magnetite via iron(II) hydroxide and green rust}

Nicolas Börsig a,*, Andreas C. Scheinost ${ }^{\text {b,c }}$, Samuel Shaw ${ }^{\text {d }}$, Dieter Schild ${ }^{\text {e }}$, Thomas Neumann a,f

${ }^{\text {a }}$ Karlsruhe Institute of Technology (KIT), Institute of Applied Geosciences, Adenauerring 20b, 76131 Karlsruhe, Germany

${ }^{\mathrm{b}}$ Helmholtz-Zentrum Dresden-Rossendorf (HZDR), Institute of Resource Ecology, Bautzner Landstraße 400, 01328 Dresden, Germany

${ }^{c}$ The Rossendorf Beamline (ROBL) at ESRF, 38043 Grenoble, France

d The University of Manchester, School of Earth, Atmospheric and Environmental Sciences, Manchester, M13 9PL, United Kingdom

e Karlsruhe Institute of Technology (KIT), Institute for Nuclear Waste Disposal, Hermann-von-Helmholtz-Platz 1, 76344 Eggenstein-Leopoldshafen, Germany

${ }^{\mathrm{f}}$ Technical University of Berlin, Institute of Applied Geoscience, Ernst-Reuter-Platz 1, 10587 Berlin, Germany

* Corresponding author: Tel.: +49 721 608-44878; nicolas.boersig@kit.edu (N. Börsig)

Keywords: selenite, selenate, selenide, iron oxide, reduction, oxidation, co-precipitation, immobilization, TEM, XPS, XAS, EXAFS

\section{Abstract}

Environmental and health hazards associated with the trace element selenium are mainly related to the presence of the highly mobile selenium oxyanions selenite and selenate (oxidation states IV and VI). In this study, we investigated the immobilization of dissolved selenite and selenate during the formation of magnetite in coprecipitation experiments based on the progressive oxidation of an alkaline, anoxic $\mathrm{Fe}^{2+}$ system ( $\mathrm{pH}$ 9.2). Up to initial selenium concentrations of $10^{-3} \mathrm{~mol} / \mathrm{L}$ (mass/volume ratio $=3.4 \mathrm{~g} / \mathrm{L}$ ), distribution coefficient values $\left(\log \mathrm{K}_{\mathrm{d}}\right)$ of 3.7 to $5.1 \mathrm{~L} / \mathrm{kg}$ demonstrate high retention of selenium oxyanions during the mineral formation process. This immobilization is due to the reduction of selenite or selenate, resulting in the precipitation of sparingly soluble selenium compounds. By X-ray diffraction analysis, these selenium compounds were identified as crystalline trigonal elemental selenium that formed in all coprecipitation products following magnetite formation. Time-resolved analysis of selenium speciation during magnetite formation and detailed spectroscopic analyses of the solid phases showed that selenium reduction occurred under anoxic conditions during the early phase of the coprecipitation process via interaction with iron(II) hydroxide and green rust. Both minerals are the initial Fe(II)-bearing precipitation products and represent the precursor phases of the later formed magnetite. Spectroscopic and electron microscopic analysis showed that this early selenium interaction leads to the formation of a nanoparticulate iron selenide phase [FeSe], 
which is oxidized and transformed into gray trigonal elemental selenium during the progressive oxidation of the aquatic system. Selenium is retained regardless of whether the oxidation of the unstable iron oxides leads to the formation of pure magnetite or other iron oxide phases, e.g. goethite. This reductive precipitation of selenium induced by interaction with metastable Fe(II)containing iron oxide minerals has the potential to influence the mobility of selenium oxyanions in contaminated environments, including the behavior of ${ }^{79} \mathrm{Se}$ in the near-field of nuclear waste repositories.

\section{Introduction}

The trace element selenium (Se) is of special concern because of the extremely fine line between its opposing properties: At low concentrations, it is an essential nutrient for many organisms, at slightly higher quantities, however, it becomes a toxic contaminant ${ }^{1}$. In addition, selenium occurs in high-level nuclear waste (HLW) in the form of the long-lived, harmful radionuclide ${ }^{79} \mathrm{Se}$, which plays an important role in long-term safety assessments of deep geological repositories ${ }^{2,3}$.

In nature selenium can occur in five different oxidation states (-II, -I, 0, IV, VI). Of particular relevance are the two higher oxidations states, where selenium forms the oxyanions selenite $\left[\mathrm{Se}^{\mathrm{IV}} \mathrm{O}_{3}{ }^{2-}\right]$ and selenate $\left[\mathrm{Se}^{\mathrm{VI}} \mathrm{O}_{4}{ }^{2-}\right]$. In aquatic systems, both selenite and selenate occur in the form of well soluble species, which are generally highly mobile due to their limited interaction with geological materials ${ }^{4,5}$. By contrast, selenium species of the oxidation states $\mathrm{Se}(-\mathrm{II}), \mathrm{Se}(-$ I) and $\operatorname{Se}(0)$ are characterized by forming sparingly soluble compounds, including metal selenides or elemental $\mathrm{Se}^{6}$. The oxidation state is therefore the key factor determining the biogeochemical behavior of selenium, since parameters such as solubility, mobility, bioavailability and toxicity mainly depend on the occurrence of dissolved selenium species ${ }^{7-9}$. For this reason, environmental health and safety hazards associated with selenium are primarily related to the presence or absence of selenium oxyanions.

Regarding the oxidation state of selenium in HLW, recent research has demonstrated that ${ }^{79} \mathrm{Se}$ occurs as Se(-II) in spent nuclear fuel ${ }^{10,11}$. Due to the reducing conditions predicted in deep HLW repositories, formation of mobile selenium species is unlikely. The expected predominant selenium oxidation state in vitrified HLW arising from nuclear fuel reprocessing plants, however, is $\mathrm{Se}(\mathrm{IV})$ in the form of selenite ${ }^{12}$. Moreover, it cannot be fully excluded that oxidation processes induced by long-term irradiation could lead to a transformation to Se(VI) or selenate, respectively ${ }^{12}$. The selenium oxidation state in HLW and the accompanying dominant selenium species thus depend on the waste type. 
The iron oxide magnetite $\left[\mathrm{Fe}_{3} \mathrm{O}_{4}\right]$ is widespread in nature, and a common mineral in sediments and soils. Furthermore, magnetite is predicted to be the most abundant corrosion product of the steel canisters (technical barrier) under the expected alkaline, anoxic conditions in the nearfield of a HLW repository ${ }^{13-16}$. The corrosion of elemental iron to magnetite is, however, not a single reaction, but involves an intermediate stage, which is associated with the presence of precursor phases such as iron(II) hydroxide $\left[\mathrm{Fe}(\mathrm{OH})_{2}\right]$ or green rust [GR, $\left.\left[\mathrm{Fe}^{\mathrm{II}}{ }_{(1-\mathrm{x})} \mathrm{Fe}^{\mathrm{III}} \mathrm{x}(\mathrm{OH})_{2}\right]^{\mathrm{x}+} \cdot\left[(\mathrm{x} / \mathrm{n}) \mathrm{A}^{\mathrm{n}-} \cdot \mathrm{mH}_{2} \mathrm{O}\right]^{\mathrm{x}-}\right]{ }^{17}$. Due to the relevance of magnetite and its precursors in various environmental systems, their influence on the behavior of dissolved selenium oxyanions has been investigated in previous studies. It was found that mineral phases that contained a reduced iron species (i.e. Fe(II)) are able to reduce selenium oxyanions under anoxic conditions. Besides magnetite ${ }^{18}$, this includes the minerals iron(II) hydroxide ${ }^{19,20}$, GR ${ }^{21-23}$ as well as elemental iron ${ }^{24-27}$, iron(II) sulfides ${ }^{28,29}$ or Fe $^{2+}$ adsorbed on clay minerals ${ }^{30}$. Since reduction of selenium oxyanions causes the formation of sparely soluble compounds, this interaction generally results in the immobilization selenium. These selenium compounds are either elemental $\mathrm{Se}$ or iron selenides like $\mathrm{FeSe}$ and $\mathrm{Fe}_{7} \mathrm{Se}_{8}{ }^{18}$, and the nature of the products varies depending on the iron-bearing phases, the hydrogeochemical conditions, and the reduction kinetics. Kinetic rather than thermodynamic control of reduction products may explain why the majority of the above-mentioned studies showed the formation of elemental Se ${ }^{19-21,23,28,30,31}$ and only a few studies identified iron selenides ${ }^{18,24,29}$. This can be attributed to the fact that reduction to $\mathrm{Se}(-\mathrm{II})$ and formation of iron selenides is limited to a rapid reduction of selenium oxyanions ${ }^{29}$.

However, retention of selenium oxyanions during the formation of magnetite has never been investigated in detail, although it is probable that both also interact in an early stage, during the mineral formation process. This applies, for instance, to the formation of magnetite due to the corrosion of elemental iron, which represents an important process in the above-mentioned surroundings of geological repositories. Another example is the formation of magnetite by biologically or abiotically induced transformation of instable iron bearing minerals in natural sediments and soils ${ }^{32,33}$. It is known that mineral formation processes can positively affect the immobilization of dissolved species. In case of selenium oxyanions, this was already demonstrated for the formation of hematite or goethite via ferrihydrite ${ }^{34,35}$.

In our study, we examined the processes that lead to the immobilization of selenite or selenate during the formation and growth of magnetite and/or its precursor phases. The aim of this work was to identify and to characterize the selenium retention mechanisms during iron 
(oxyhydr)oxide formation and to assess the immobilization in regard to the retention capacity and stability of the associated selenium species. To achieve this, we performed coprecipitation experiments with magnetite and selenium oxyanions at alkaline $\mathrm{pH}$, which is relevant to the condition associated with the near-field of bentonite or concrete back-filled repositories ${ }^{14}$. Furthermore, another key aspect was to investigate in which way a change of the redox conditions affects the selenium retention. For this reason, the redox conditions were changed from initial anoxic to later oxic conditions during the experiments. With the help of hydrochemical data and a detailed analysis of the precipitation products by spectroscopic and electron microscopic methods, we were able to derive the processes involved in the selenium immobilization.

\section{Materials and Methods}

\subsection{Synthesis of magnetite}

Magnetite (Mt) was synthesized in the laboratory by using a modified method of Schwertmann and Cornell ${ }^{36}$. This method was originally designed for the preparation of goethite (Gt) and is based on the progressive oxidation of an anoxic aquatic $\mathrm{Fe}^{2+}$ system. By increasing the solution $\mathrm{pH}$ from neutral to alkaline conditions, it was however possible to inhibit the formation of goethite and to produce pure magnetite. One advantage of this method is that the mechanism of formation is more similar to natural magnetite formation than alternative preparation methods based on the mixing of $\mathrm{Fe}^{2+}$ and $\mathrm{Fe}^{3+}$ solutions. For the synthesis of magnetite $5 \mathrm{~g}$ of $\mathrm{FeCl}_{2} \cdot 4$ $\mathrm{H}_{2} \mathrm{O}$ were dissolved in $500 \mathrm{ml} \mathrm{N}$-degassed Milli-Q water $(\sim \mathrm{pH} 3.5)$. After the addition of $55 \mathrm{ml}$ $1 \mathrm{M} \mathrm{KOH}$ and the immediate precipitation of a bluish green compound $(\sim \mathrm{pH} 8)$, the suspension was titrated and buffered with $25 \mathrm{ml}$ of $1 \mathrm{M} \mathrm{NaHCO}_{3}$ solution, which led to a $\mathrm{pH}$ value of $\sim 8.5$. All solutions were made of analytically pure grade chemicals and de-ionized, $\mathrm{N}_{2}$-degassed Milli-Q water $\left(18.2 \mathrm{M} \Omega \mathrm{cm}^{-1}\right)$. Continuous stirring during and after the mixing resulted in a progressive oxidation of the anoxic $\mathrm{Fe}^{2+}$ system by atmospheric oxygen. Within 48 hours, this oxygen input caused the complete transformation of the initial bluish green precipitate into a black mineral with magnetic properties. In order to analyze the initially formed precipitation products, the synthesis process was terminated after 30 minutes and 3 hours, respectively. With about $2 \mathrm{~g}$ precipitated iron oxide forming, the mass to volume ratio $(\mathrm{m} / \mathrm{V})$ between magnetite and the aqueous solution was approx. $3.4 \mathrm{~g} / \mathrm{L}$ in these batch experiments. At the end of the 48 hour reaction time, the black precipitates were decanted and centrifuged. While a sample of the solutions was taken for the analysis of the iron concentration and $\mathrm{pH}$, a part of the solids were washed 3 times with Milli-Q. The washed magnetite samples were then dried at moderate 
temperatures of $40^{\circ} \mathrm{C}$. The remaining part of the solid sample was dried without washing in order to preserve the original characteristics of the synthesized sample. After drying, the aggregated particles were ground with an agate mortar and stored until analysis. In case of the initial precipitation products (magnetite precursor after 30 minutes and 3 hours), the samples were not washed or dried after the respective reaction time but were stored in their original synthesis solution. This was done to avoid further oxidation and crystallization processes after the terminated reaction with oxygen.

\subsection{Coprecipitation experiments}

The general procedure as well as the subsequent sample preparation of the coprecipitation experiments were almost identical to those of the described synthesis of pure magnetite. To investigate the behavior of selenite or selenate during the coprecipitation with magnetite, various volumes of selenium stock solutions were added to the dissolved $\mathrm{Fe}^{2+}$ prior to the beginning of the first mineral precipitation. These stock solutions were prepared by dissolving defined quantities of $\mathrm{Na}_{2} \mathrm{SeO}_{3}$ or $\mathrm{Na}_{2} \mathrm{SeO}_{4} \cdot 10 \mathrm{H}_{2} \mathrm{O}$ in $\mathrm{N}_{2}$-degassed Milli-Q water to receive total selenium concentrations of $0.1 \mathrm{~mol} / \mathrm{L}$ and $1.0 \mathrm{~mol} / \mathrm{L}$. The added selenium stock solution volumes were calculated to obtain initial selenite and selenate concentrations of $10^{-4}$ $10^{-2} \mathrm{~mol} / \mathrm{L}$ after the mixing of all solutions $(\mathrm{m} / \mathrm{V}$ ratio $=3.4 \mathrm{~g} / \mathrm{L})$. Indeed, these relatively high concentrations reflect extreme natural amounts but were necessary to increase the concentration of selenium in the solid samples. This improved the selenium detection in the subsequent analyses. After the completed mineral formation, the residual selenium concentration in solution was analyzed to calculate the amount of removed selenite or selenate. The reaction time of the coprecipitation studies was also 48 hours. However, in order to allow a timeresolved investigation of the selenium retention behavior, the precipitates and solutions were also collected and analyzed after reaction times of 30 minutes and 3 hours.

\subsection{Analytical techniques}

The selenium and iron concentrations in the aqueous phase were determined by Inductively Coupled Plasma Optical Emission Spectrometry (ICP-OES; Varian 715ES) or Inductively Coupled Plasma Mass Spectrometry (ICP-MS; X-Series 2, Thermo Fisher Scientific Inc.) depending on the solution concentrations. X-Ray Diffraction (XRD) was used for analysis of the purity and mineral composition of the synthesized solid materials and was performed on a Bruker D8 Advance X-ray diffractometer $(\mathrm{Cu} \mathrm{K} \alpha)$. In order to calculate the Specific Surface Areas (SSA) of magnetite and its precursor phase, BET measurements were performed using a Quantachrome Autosorb 1-MP and 11-point BET-argon isotherms recorded at the temperature 
of liquid argon (87.3K). Prior to the measurement, the sample were outgassed in vacuum at $95^{\circ} \mathrm{C}$ overnight to remove water and other volatile surface contaminations. The total selenium content of the solid phases was determined by polarized Energy Dispersive X-ray Fluorescence Spectroscopy (pEDXRF) using an Epsilon 5 (PANalytical). Electron microscopy with Energy Dispersive X-ray Spectroscopy (EDX) was used to characterize the morphology, particle size, and detailed chemical composition of the solid phases. Images were recorded using a LEO 1530 (Zeiss Inc.) Scanning Electron Microscope (SEM) with a NORAN System SIX (Thermo Electron Corp.) EDX-System or alternatively via a FEI Talos F200X analytical Scanning/Transmission Electron Microscope (S/TEM) operated at $200 \mathrm{kV}$. The TEM is equipped with an integrated Super-X EDS system with 4 windowless silicon drift detectors (SDD). To examine the selenium oxidation state and to identify elemental composition of the surface area, X-ray Photoelectron Spectroscopy (XPS) measurements were performed using a PHI 5000 VersaProbe II (ULVAC-PHI Inc.). Detailed information about measurement parameters and sample preparation are described in the Supporting Information.

X-ray Absorption Spectroscopy (XAS) analysis was carried out on selected Se-bearing samples to identify the selenium oxidation state as well as the nature of the molecular selenium structure. Se K-edge X-ray Absorption Near-Edge Structure (XANES) and Extended X-ray Absorption Fine-Structure (EXAFS) spectra were collected at the Rossendorf Beamline (ROBL) at ESRF (Grenoble, France). Measurement parameters and sample preparation are described in detail in the Supporting Information. The evaluation of the XAS data, including dead time correction of the fluorescence signal, energy calibration and the averaging of single scans were performed with the software package SixPack (www.sams-xrays.com/sixpack). Normalization, transformation from energy into $\mathrm{k}$ space, and subtraction of a spline background was performed with WinXAS using routine procedures ${ }^{37}$. The $k$-weighted EXAFS data were fit with WinXAS using theoretical back-scattering amplitudes and phase shifts calculated with FEFF $8.2^{38}$. Statistical analysis of spectra was performed with the ITFA program package ${ }^{39}$. Spectra of selenium reference samples (selenite solution as well as crystalline achavalite, ferroselite, and gray elemental Se) were taken from Scheinost and Charlet ${ }^{18}$.

\section{Results and Discussion}

\subsection{Characterization of synthesized magnetite and its precursor phases}

Before the coprecipitation of selenite and selenate with magnetite was examined, the properties of the synthesized iron oxides were characterized by several techniques. XRD patterns of synthesized magnetite after $48 \mathrm{~h}$ showed that pure magnetite $\left[\mathrm{Fe}_{3} \mathrm{O}_{4}\right]$ was formed without any 
evidences of goethite contaminations. For the magnetite precursor phases (reaction time $30 \mathrm{~min}$ or $3 \mathrm{~h}$ ), the XRD analysis revealed that these samples consist of a mixture of different mineral phases (SI Fig. A.1). The XRD patterns are dominated by a broad peak, which can be attributed to the presence of an amorphous or poorly crystalline mineral phase. In their description of the synthesis method, Schwertmann and Cornell ${ }^{36}$ point out that the oxidation of an anoxic aquatic $\mathrm{Fe}^{2+}$ system takes place with the participation of iron(II) hydroxide phases. These phases are the immediate precipitation products after the first increase of the solution $\mathrm{pH}$ and also represent the unstable precursors of the later formed goethite (here magnetite). The presence of amorphous or poorly crystalline iron hydroxides in the early phase of coprecipitation is therefore very likely. Furthermore, one can identify peaks that are associated with the presence of small amounts of crystalline iron oxide phases such as magnetite and GR, whereby the early magnetite formation is probably due to small quantities of dissolved oxygen in the synthesis solution. Besides that, small amounts of (hydrogen)carbonate salts occur in these unwashed samples (precipitated background electrolyte). BET measurements gave specific surface areas (SSA) of $32 \mathrm{~m} / \mathrm{g}$ for magnetite and $264 \mathrm{~m} / \mathrm{g}$ for its precursor phase with a reaction time of 30 min. The determined SSA of magnetite is consistent with published values in the literature. It is known that the SSA of synthesized magnetite can vary widely depending on its formation pathway and that, in particular, magnetite precipitation from a solution can lead to particles with a SSA of up to $100 \mathrm{~m} / \mathrm{g}{ }^{17}$.

The microscopic characterization (SEM) revealed that the pure magnetite consists of aggregated particles with a size of approximately $50 \mathrm{~nm}$ (SI Fig. A.2). In case of the magnetite precursor phase, the high SSA of $264 \mathrm{~m} / \mathrm{g}$ is in good agreement with the XRD results and the assumption that this sample type is dominated by a poorly crystalline mineral phase. However, one has to consider that the magnetite precursor consists of several mineral phases and that the required sample drying before the BET analysis might has changed the characteristics of this sample type. By XPS analysis, it was shown that the near-surface region of the unwashed magnetite phases consisted primarily of $\mathrm{Fe}$ and $\mathrm{O}$ as well as smaller amounts of $\mathrm{Cl}, \mathrm{K}$, and $\mathrm{Na}$ (SI Table A.2). This chemical composition is likely caused by adsorption of dissolved ionic species onto the magnetite surface. XPS analysis also enabled the determination of the $\mathrm{Fe}(\mathrm{II}) / \mathrm{Fe}_{\text {total }}$ ratio (here defined as $\mathrm{x}_{\mathrm{Fe}(\mathrm{II})}$ ) on the mineral surface. This evaluation method is described in Huber et al. ${ }^{40}$ and is based on a comparison between the Fe $2 \mathrm{p}$ spectra of a sample and the Fe $2 p$ spectra of references with known $\mathrm{X}_{\mathrm{Fe}(\mathrm{II})}$ values. Hematite and a freshly prepared magnetite were used as references, which is why, this method can only be applied for iron oxides but not for iron hydroxides or iron oxyhydroxides. With a determined $\mathrm{x}_{\mathrm{Fe}(\mathrm{II})}$ value of 
0.14 the results indicate that the synthesized magnetite is partially oxidized to maghemite $[\gamma-$ $\left.\mathrm{Fe}_{2} \mathrm{O}_{3}\right]$ at the end of synthesis process, which could be a consequence of the oxygen contact during the sample drying. Maghemite $\left(\mathrm{x}_{\mathrm{Fe}(\mathrm{II})}=0\right)$ is an oxidation product of magnetite $\left(\mathrm{x}_{\mathrm{Fe}(\mathrm{II})}=\right.$ 0.33 ) after contact with atmospheric oxygen, and both minerals represent the end members of a solid solution series ${ }^{36,41}$. However, since there is also no sign of a brownish-red color of the black precipitate, which would be typical for the occurrence of maghemite, one can assume that mainly the surface region is affected by oxidation, but not the bulk phase. This assumption is supported by the fact that oxidation of magnetite in maghemite on the surface of magnetite particles can inhibit further oxidation processes ${ }^{42}$.

\subsection{Removal of selenite and selenate by coprecipitation}

The analysis of the residual selenium concentration allowed the determination of the selenite or selenate amount that was removed during the coprecipitation with magnetite. Figure 1 shows the quantities of selenium associated with the solid phase as a function of the selenium concentration at $\mathrm{pH}$ 9.2. Both datasets, the percentage of removed selenium depended on the initial selenium concentration (Fig. 1a) as well as the selenium uptake depending on the selenium equilibrium concentration (Fig. 1b), indicate that coprecipitation represents a highly efficient process to immobilize dissolved selenium oxyanions. However, the results also demonstrate that the selenium retention is affected by the speciation. For selenate, the uptake by coprecipitation decreases with higher initial concentrations and the selenate sorption reaches an upper limit at $\sim 1 \mathrm{~mol} / \mathrm{kg}$. By contrast, retention of selenite is not influenced by higher initial selenite amounts and even at concentrations of $10^{-2} \mathrm{~mol} / \mathrm{L}$ all available selenite is removed. The same applies to the total selenite sorption, which rises to values of up to $\sim 3 \mathrm{~mol} / \mathrm{kg}$ and shows no indication of a sorption limit in the tested concentration range.

\subsection{Development of the coprecipitation products within the $\mathrm{Fe}-\mathrm{Se}-\mathrm{H}_{2} \mathrm{O}$ system}

Table 1 compiles the main properties of samples from the coprecipitation experiments, which were conducted at different initial selenite or selenate concentrations. Besides detailed hydrochemical data and the calculated selenium uptake in form of the sorbed selenium percentage and the distribution coefficient $\left(\log \mathrm{K}_{\mathrm{d}}\right)$, the table contains a summarized overview of solids analysis. Regarding the total selenium content of the solid phases (EDXRF results), one can observe a correlation with the initial concentration respectively the sorbed selenium percentage. Increasing concentrations of dissolved selenite or selenate lead to higher selenium contents of the coprecipitation products, whereby selenite causes higher absolute quantities than selenate. 
Table 1 Equilibrium concentrations of iron and selenium, selenium removal (in $\%$ and $\log \mathrm{K}_{\mathrm{d}}$ ) and the mineral composition (Mt: magnetite, $\mathrm{Gt}$ : goethite, $\mathrm{Se}^{0}$ : trigonal elemental selenium) of selected samples of coprecipitation experiments with different initial selenium amounts; " $\mathrm{C}$ " $c(\mathrm{Se})_{0}=$ " $X "$. $10^{-3} \mathrm{~mol} / \mathrm{L}$.

\begin{tabular}{|c|c|c|c|c|c|c|c|c|c|c|}
\hline$\#$ & Se species & Sample & $\operatorname{Mineral}(\mathbf{s})^{a}$ & $\begin{array}{r}\mathrm{Se}^{b} \\
{[\mathrm{ppm}]}\end{array}$ & $\mathbf{p H}^{c}$ & $\begin{array}{r}\mathrm{c}(\mathrm{Fe}) \\
{[\mathrm{mol} / \mathrm{L}]}\end{array}$ & $\begin{array}{r}\mathrm{c}(\mathrm{Se})_{0} \\
{[\mathrm{~mol} / \mathrm{L}]}\end{array}$ & $\begin{array}{r}\mathrm{c}(\mathrm{Se}) \\
{[\mathrm{mol} / \mathrm{L}]}\end{array}$ & $\begin{array}{r}\text { Se sorbed } \\
{[\%]}\end{array}$ & $\begin{array}{l}\log K_{\mathrm{d}} \\
{[\mathrm{L} / \mathrm{kg}]}\end{array}$ \\
\hline 1 & --- & Mt (pure) & Mt & bdl & 8.9 & 7.96E-07 & $0.00 \mathrm{E}+00$ & bdl & - & - \\
\hline 2 & Selenate & $\mathrm{Se}(\mathrm{VI}) \mathrm{CopMt}^{0.1}$ & Mt & 1700 & 9.2 & $6.45 \mathrm{E}-08$ & 1.02E-04 & $5.71 \mathrm{E}-07$ & 99.4 & 4.72 \\
\hline 3 & $"$ & $\mathrm{Se}(\mathrm{VI}) \mathrm{CopMt}^{0.5}$ & $\mathrm{Mt}+\mathrm{Se}^{0}$ & 9900 & 9.1 & 4.16E-07 & 5.11E-04 & 2.73E-06 & 99.5 & 4.74 \\
\hline 4 & $"$ & $\mathrm{Se}(\mathrm{VI}) \mathrm{CopMt}^{1}$ & $\mathrm{Mt}+\mathrm{Se}^{0}$ & 16000 & 9.2 & 4.51E-07 & $1.02 \mathrm{E}-03$ & 5.66E-05 & 94.5 & 3.70 \\
\hline 5 & $"$ & $\mathrm{Se}(\mathrm{VI}) \mathrm{CopMt}^{3}$ & $\mathrm{Mt}+\mathrm{Se}^{0}$ & 40000 & 9.0 & 1.69E-06 & 3.07E-03 & $5.84 \mathrm{E}-04$ & 81.0 & 3.10 \\
\hline 6 & $"$ & $\mathrm{Se}(\mathrm{VI}) \mathrm{CopMt}^{5}$ & $\mathrm{Mt}+\mathrm{Se}^{0}$ & 58000 & 9.3 & 3.47E-07 & $5.11 \mathrm{E}-03$ & $1.95 \mathrm{E}-03$ & 61.9 & 2.68 \\
\hline 7 & $"$ & $\mathrm{Se}(\mathrm{VI}) \mathrm{CopMt}^{10}$ & $\mathrm{Mt}+\mathrm{Gt}+\mathrm{Se}^{0}$ & 120000 & 9.1 & $3.28 \mathrm{E}-06$ & $1.02 \mathrm{E}-02$ & $6.95 \mathrm{E}-03$ & 32.0 & 2.14 \\
\hline 8 & Selenite & Se(IV)CopMt ${ }^{0.1}$ & Mt & 1700 & 9.2 & $5.23 \mathrm{E}-08$ & $1.00 \mathrm{E}-04$ & $5.84 \mathrm{E}-07$ & 99.4 & 4.70 \\
\hline 9 & $"$ & $\mathrm{Se}(\mathrm{IV}) \mathrm{CopMt}^{0.5}$ & $\mathrm{Mt}+\mathrm{Se}^{0}$ & 8600 & 9.2 & $6.41 \mathrm{E}-08$ & 5.02E-04 & $2.25 \mathrm{E}-06$ & 99.6 & 4.82 \\
\hline 10 & $"$ & Se(IV)CopMt ${ }^{1}$ & $\mathrm{Mt}+\mathrm{Se}^{0}$ & 17000 & 9.1 & 2.53E-07 & $1.00 \mathrm{E}-03$ & $5.10 \mathrm{E}-06$ & 99.5 & 4.76 \\
\hline 11 & $"$ & Se(IV)CopMt ${ }^{3}$ & $\mathrm{Mt}+\mathrm{Se}^{0}$ & 48000 & 9.0 & $2.80 \mathrm{E}-07$ & $3.01 \mathrm{E}-03$ & 8.61E-06 & 99.7 & 5.01 \\
\hline 12 & $"$ & Se(IV)CopMt ${ }^{5}$ & $\mathrm{Mt}+\mathrm{Se}^{0}$ & 74000 & 9.3 & $6.56 \mathrm{E}-06$ & $5.02 \mathrm{E}-03$ & $1.02 \mathrm{E}-05$ & 99.8 & 5.16 \\
\hline 13 & $"$ & Se(IV)CopMt ${ }^{10}$ & $\mathrm{Mt}+\mathrm{Gt}+\mathrm{Se}^{0}$ & 140000 & 9.5 & 1.04E-06 & $1.00 \mathrm{E}-02$ & 4.30E-05 & 99.6 & 4.84 \\
\hline
\end{tabular}

${ }^{a}$ Mineral composition (XRD analysis). ${ }^{b}$ Se content of the solid phase (EDXRF analysis). ${ }^{\mathrm{c}} \mathrm{pH}$ after synthesis/coprecipitation Furthermore, one could observe that coprecipitation at high selenium concentrations resulted in the formation of dark gray compounds, whose colors differ from the black reaction product of the pure magnetite synthesis. The analysis of the mineral composition demonstrated that, following the coprecipitation process, almost all samples contained gray trigonal elemental Se (PDF 86-2246; SI Table A.1). Gray elemental Se could be identified by means of its characteristic peaks, which occurred in the XRD plots of all samples with higher selenium contents ( $\geq 1 \mathrm{wt} \% \mathrm{Se}$ ) beside the peaks of magnetite (SI Fig. A.3). Only the samples, whose total selenium concentrations were too low to successfully detect crystalline Se due to the XRD detection limit showed no signs for mineral phases other than magnetite. The coprecipitation of selenium oxyanions and magnetite thus leads to the reduction of selenite or selenite, resulting in the precipitation of sparingly soluble elemental Se. This reductive precipitation of elemental Se, however, does not have much influence on the iron oxide formation process as neither the final $\mathrm{pH}$, residual iron concentration nor the nature of the formed iron oxide are affected by high concentrations of selenite or selenate (Table 1). Only the formation of pure magnetite is no longer possible in the case of extremely high initial selenium concentrations, which instead cause the formation of magnetite-goethite mixed phases. Furthermore, samples of comparative coprecipitation experiments showed that the precipitation of gray elemental Se is not affected by the nature of the final iron (oxyhydr)oxide product. Regardless of whether the coprecipitation process leads to the formation of pure magnetite or also iron(III) oxyhydroxides like goethite and lepidocrocite, formation of elemental Se can be observed (SI Fig. A.4).

Evaluation of the $\mathrm{Fe}(\mathrm{II}) / \mathrm{Fe}_{\text {total }}$ ratio of the final coprecipitation products yielded similar results $\left(\mathrm{x}_{\mathrm{Fe}(\mathrm{II})}=0.09-0.13\right)$ as those obtained for Se-free magnetite (SI Table A.2). Although the 
coprecipitated magnetite is affected by a partial oxidation to maghemite, the oxidation process is not enhanced by the presence of dissolved selenium oxyanions. Just like the Se-free magnetite, the near-surface region of the unwashed final coprecipitation products contains, besides $\mathrm{Fe}$ and $\mathrm{O}$, certain variable amounts of $\mathrm{C}, \mathrm{Cl}, \mathrm{K}$ and $\mathrm{Na}$, which indicate adsorption of dissolved ionic species or precipitation of salt phases. In addition, the final precipitates also consist of small shares of selenium ( $\sim 0.7$ at $\%$ at initial concentrations of $\left.10^{-3} \mathrm{~mol} / \mathrm{L}\right)$ resulting from the presence of elemental Se.

In order to investigate the temporal development of the coprecipitation processes within the $\mathrm{Fe}$ $\mathrm{Se}-\mathrm{H}_{2} \mathrm{O}$ system, we analyzed samples representing different stages of the coprecipitation process. This examination included a detailed characterization of the precipitation products by XRD (Fig. 2). The results show that, at the end of the progressive oxidation (reaction time 48 hour), the coprecipitation products of both selenium systems only contain magnetite and elemental Se (cf. Table $1 \&$ SI Fig. A.3). In contrast, the precipitates that represent the early anoxic or suboxic stage of the magnetite formation process (reaction time $30 \mathrm{~min}$ or $3 \mathrm{~h}$ ) consist of a number of different crystalline mineral phases. This includes iron oxides such as magnetite and GR, (hydrogen)carbonate salts (precipitated background electrolyte) as well as gray trigonal elemental Se. Since the hydrochemical system mainly contains the anions chloride and (hydrogen)carbonate, it can be assumed that the GR phase is primarily chloride green rust $\left[\mathrm{GR}\left(\mathrm{Cl}^{-}\right)\right]$or carbonate green rust $\left[\mathrm{GR}\left(\mathrm{CO}_{3}{ }^{2-}\right)\right]^{43,44}$. Formation of selenite or selenate green rust ${ }^{45}$ can, however, be excluded (cf. 3.4.2).

The short-term samples presumably also contain amorphous or poorly crystalline iron(II) hydroxide, which might be responsible for the broad peak in the XRD plot. That the short-term coprecipitation samples, in contrast to the final products, mainly consist of iron hydroxides rather than iron oxides could be confirmed by the analysis of the $\mathrm{O} 1 \mathrm{~s}$ spectra. Based on the comparison of the measured $\mathrm{O} 1 \mathrm{~s}$ binding energies with references, the dominance of hydroxide $\left(\mathrm{OH}^{-}\right)$over oxide $\left(\mathrm{O}^{2-}\right)$ compounds could be illustrated (SI Fig. A.5). Due to this dominance of iron hydroxides, it was, however, not possible to apply the previous described evaluation

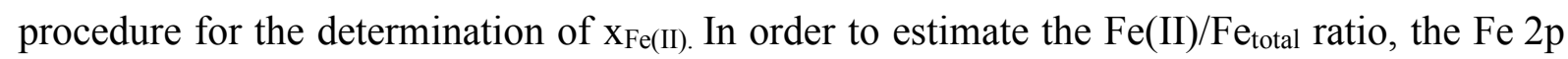
spectra of the analyzed coprecipitation samples were therefore directly compared with the published Fe 2p spectra of stoichiometric $\mathrm{GR}\left(\mathrm{CO}_{3}{ }^{2-}\right) \quad\left[\mathrm{Fe}_{4} \mathrm{Fe}^{\mathrm{II}} \mathrm{Fe}_{2}(\mathrm{OH})_{12} \mathrm{CO}_{3} \cdot 3 \mathrm{H}_{2} \mathrm{O}\right.$; $\left.\mathrm{X}_{\mathrm{Fe}(\mathrm{II})}=0.67\right]^{46}$. Since the Fe $2 p$ spectra are almost identical (SI Fig. A.5), one can assume that the proportion of $\mathrm{Fe}(\mathrm{II})$ lies also in the range of $\mathrm{x}_{\mathrm{Fe}(\mathrm{II})}=\sim 0.67$ (SI Table A.2). 
Regarding the mineral composition as well as the relative proportions of the minerals (estimated from peak intensities), there is hardly any difference between reaction times of $30 \mathrm{~min}$ or $3 \mathrm{~h}$. The only exceptions are elemental Se, which can only be identified in the samples with a reaction time of 3 hours, and the GR phase, whose proportion seems to increase (Fig. 2). The relatively large proportion of GR in the short-term coprecipitation samples ( $30 \mathrm{~min}$ and $3 \mathrm{~h}$ ) is particularly noticeable in comparison to the equivalent samples from the Se-free system, which show scarcely any evidence of GR during the early phase of the magnetite formation process (cf. SI Fig. A.1). Precipitation of GR therefore appears to be associated with the presence of dissolved selenium oxyanions.

Furthermore, since the proportion of magnetite does not increase within the first 3 hours, one can conclude that the magnetite formation requires a certain period of time. This is also confirmed by the macroscopic observation that the color change of the precipitate from bluish green to black lasts several hours. Formation of magnetite is thus the result of the progressive oxidation of the system, which causes the complete transformation of the primarily formed $\mathrm{Fe}(\mathrm{II})$-rich iron oxide phases into magnetite. It is known that both iron(II) hydroxide and GR are only stable under anoxic conditions and are oxidized to magnetite or iron(III) oxyhydroxides like goethite or lepidocrocite in contact with air or dissolved oxygen, respectively ${ }^{43,47}$. The nature of the oxidation product thereby depends on the general hydrochemical conditions, whereby low oxidation rates as well as an alkaline $\mathrm{pH}$ favor the formation of magnetite $43,44,48-$ 50 .

\subsection{Reductive precipitation of selenium oxyanions}

Besides via XRD, precipitation of elemental Se could also be verified by SEM/EDX and XPS results. SEM images of two analyzed samples from each selenium system - selenite or selenate - are shown in Figure 3 and SI Figure A.6 \& A.7, respectively. These samples were selected because of their high selenium content (6-7 wt\%), arising from initial selenite or selenate concentrations of $5 \cdot 10^{-3} \mathrm{~mol} / \mathrm{L}$. The images of both samples indicate the formation of elongated (1-2 $2 \mathrm{~m}$ ) euhedral Se crystals (identified via EDX; SI Fig. A.6 or A.7) that are embedded in the magnetite matrix. Although the elemental Se crystals vary in size, they are all significantly larger than the magnetite particles with average sizes of $25-50 \mathrm{~nm}$. Moreover, the XPS analysis prove that, at the end of the 48-hour reaction time [SeCopMt], selenium is present in the oxidation state $\mathrm{Se}(0)$ (SI Table A.2). This confirms the previous findings, according to which the coprecipitation of selenite or selenate with magnetite ends in the formation of elemental Se. 
That interaction between reduced iron minerals and selenium oxyanions can cause a reductive selenium precipitation and hence an immobilization was also observed in previous publications. Formation of $\mathrm{Se}(0)$ was demonstrated by studies regarding selenite or selenate reduction by ZVI ${ }^{26,27,51}$ or Fe(II)-bearing mineral phases like iron(II) hydroxide ${ }^{19,20,31}$ and GR ${ }^{21-23}$. By contrast, sorption studies on magnetite ${ }^{18,29}$ showed that reduction processes can also lead to the formation of various iron selenide compounds. This also applies to the interaction of selenate with nanoparticulate ZVI ${ }^{24}$. However, even under consistently anoxic conditions, interaction of selenium oxyanions with reduced iron phases does not always cause a reductive selenium precipitation, which was confirmed in several sorption studies ${ }^{52-54}$. Concerning the selenium reduction process, this suggests that the formation pathway of magnetite and the other involved iron oxide phases play a crucial role.

In addition, the time-resolved XRD analysis of the coprecipitation process shows that gray elemental Se occurs for the first time after 3 hours and that the intensity of the Se peaks and hence the relative elemental Se content increases in the subsequent period (Fig. 2). The formation of elemental $\mathrm{Se}$, therefore, does not take place in the very beginning of the coprecipitation process, but in a later stage. Indications for the presence of crystalline Sebearing minerals other than elemental Se are not visible.

The results of the development of the residual selenium concentrations, however, clearly demonstrate that most of the initial selenite or selenate content is already removed from solution after reaction times of 30 min (Fig. 4). This is confirmed by the XPS results of the respective solid samples [SeCopMt-30min], whose chemical composition show significant proportions of selenium. The analysis of the dissolved selenium concentration also illustrates that no selenium is released during the formation of elemental $\mathrm{Se}$ or the transformation of the iron hydroxides into magnetite.

In order to find out what retention mechanism causes the immobilization of selenite or selenate in the early stage of the coprecipitation process, the fate of selenium after reaction times of 30 min was characterized in detail. This included, among other things, an analysis of the selenium oxidation state by the determination of the selenium binding energies via XPS (SI Table A.2). The results prove that the precipitates representing the early coprecipitation stage [SeCopMt-30min] contain selenium in the oxidation stage Se(-II). Reduction of selenite and selenate thus takes place within the first minutes of the coprecipitation, in a period in which the dissolved selenium oxyanions are in contact with the Fe(II)-rich precursor phases of magnetite under anoxic conditions. 
Moreover, the absence of selenite or selenate in the precipitates demonstrates that the retention is not due to adsorption processes, which means, that the fast removal of selenium oxyanions is clearly not associated with the general rapid adsorption kinetic of selenite or selenate on iron oxide minerals ${ }^{52,54-56}$. The same also applies to selenium immobilization due to the formation of selenite or selenate GR or the incorporation of selenium oxyanions in magnetite or its precursor phases. That the coprecipitation between magnetite and dissolved oxyanions can generally lead to incorporation was demonstrated by Wang et al. ${ }^{57}$ for the oxyanion arsenate $\left[\mathrm{As}^{\mathrm{V}} \mathrm{O}_{4}{ }^{3-}\right]$. Up to now, however, there is no evidence that comparable processes could also be relevant for the selenite-magnetite or selenate-magnetite system.

S/TEM in combination with EDX analyses enabled spatially resolved observation and chemical characterization of a Se(-II)-bearing coprecipitation sample [Se(IV)CopMt-30min]. Figure 5 shows high-angle annular dark-field (HAADF) images together with relevant elemental mappings. The TEM/EDX analysis confirms the previous results indicting that the primary precipitation products consist of different mineral phases. The analyzed sample contains crystalline as well as amorphous or poorly crystalline phases. GR crystals can be identified by their distinctive hexagonal crystal shape ${ }^{58,59}$. Since they are characterized by higher levels of chloride this suggests that the GR phase is primarily $\mathrm{GR}\left(\mathrm{Cl}^{-}\right)$. In this context, one has however to consider that the analysis of carbon and therefore the detection of $\operatorname{GR}\left(\mathrm{CO}_{3}{ }^{2-}\right)$ was not possible via EDX due to the $\mathrm{C}$-containing TEM grid.

The distribution of selenium within the sample is heterogeneous. There are no signs that the selenium is bound in certain iron oxide minerals. EDX spectra of Se-rich spots are characterized by high Se and Fe contents, while their proportion of $\mathrm{O}$ tends to be lower than for Se-free spots. The latter can be seen in SI Fig. A.8, which includes a comparison between the EDX spectrum of an isolated Se-rich spot and the spectrum of the center of a GR particle, containing mainly $\mathrm{Fe}, \mathrm{O}$, and small amounts of $\mathrm{Cl}$. Therefore, higher selenium concentrations are likely associated with the occurrence of a discrete Se-Fe-bearing phase, likely iron selenide. This phase is present in the iron oxide matrix in the form of heterogeneously distributed independent particles, which tend to be located around the edges of the GR and the other iron oxides. Moreover, with sizes below $100 \mathrm{~nm}$, these iron selenide particles are also rather small.

\subsection{Temporal evolution of the selenium speciation and the retention mechanism}

Results of Se K-edge XAS analyses were used to characterize the selenium oxidation state (XANES) as well as the nature of the local selenium structure (EXAFS) during the 
coprecipitation process. For this purpose, coprecipitation products of both selenium systems were analyzed after reaction times of $30 \mathrm{~min}, 3 \mathrm{~h}$ and $48 \mathrm{~h}$ (cf. samples Fig. 2).

Figure 6 shows the Se K-edge XANES spectra of the analyzed samples together with reference spectra of the minerals ferroselite $\left[\mathrm{FeSe}_{2}\right]$, achavalite [FeSe], and, gray elemental Se. A comparison of the reference spectra illustrates that the oxidation states $\mathrm{Se}(0), \mathrm{Se}(-\mathrm{I})$, and $\mathrm{Se}(-\mathrm{II})$ are difficult to differentiate due to the very similar position of their absorption edge $(12.6553-12.6560 \mathrm{keV})$. However, since the shape of the white line varies widely, one can use this feature to identify the selenium oxidation state. While the white line of gray Se is dominated by one significant peak, the white line of ferroselite and achavalite is of lower intensity and, in case of achavalite, also characterized by two maxima. Similar to achavalite, the samples with reaction times of $30 \mathrm{~min}$ [SeCopMt-30min] show white lines of relatively low intensities and two maxima, confirming that selenium is indeed present in the form of Se(-II). These XANES data are thus in line with the previous findings of the XPS analysis after which dissolved Se(IV) and $\mathrm{Se}(\mathrm{VI})$ oxyanions are reduced to $\mathrm{Se}(-\mathrm{II})$ in the early stage of the coprecipitation process.

However, during oxidation of the system, these Se(-II) species are transformed to elemental Se, as it can be seen from the similarity between the white lines of gray Se and the coprecipitation samples with reaction times of 3 hours [SeCopMt-3h] and 2 days [SeCopMt-2d]. In this form, the selenium stays stable, although $\mathrm{Se}(0)$ does not represent the thermodynamically most stable oxidation state under oxic conditions. Furthermore, there is no difference between samples of the selenite and selenate system, indicating that at no time of the oxidation process is the selenium behavior influenced by the initial speciation.

Regarding the selenium local structural environment, a comparison of the EXAFS Fourier transforms (FT) illustrates that spectra of the $\mathrm{Se}(0)$-bearing samples are identical to the gray $\mathrm{Se}$ reference, whereas the EXAFS FT magnitude of the Se(-II) species is clearly different from reference spectra of achavalite or ferroselite (Fig. 6). In order to check whether the samples with reaction times of 3 hours represent a spectral mixture of $\mathrm{Se}(-\mathrm{II})$ and $\mathrm{Se}(0)$ species, a statistical analysis was performed using Iterative Transformation Factor Analysis (ITFA) ${ }^{18,39}$. This ITFA included the EXAFS spectra of all coprecipitation samples as well as the spectrum of gray Se, since the previous analyses showed that the immobilized selenium should be present as gray elemental Se at the end of the coprecipitation process. Figure 7a shows the excellent match between the experimental spectra (black lines) and their reconstructions (red or blue lines) by two principal components (PC). The Varimax factor loadings (Fig. 7b) demonstrate that the gray Se reference as well as the final coprecipitation products [SeCopMt-2d] are solely 
dominated by PC 1, without any influence of PC 2. PC 1 therefore represents the occurrence of gray elemental Se. By contrast, samples of the early stage [SeCopMt-30min] are characterized only by PC 2, meaning that PC 2 epitomizes the present of the Se(-II) phase. In addition, as the samples of the intermediate stage [SeCopMt-3h] are described by both principal components, one can conclude that these samples contain indeed two different types of selenium species. A fit of the EXAFS data is therefore only useful in case of the samples representing the $\operatorname{Se}(0)$ and Se(-II) endmembers (Table 2).

Table 2 Se-K XANES edge energies and EXAFS fit results of Selenite-magnetite and Selenate-magnetite products of different reaction times $\left(S_{0}^{2}=0.9\right)$.

\begin{tabular}{|c|c|c|c|c|c|c|c|c|c|c|c|}
\hline \multirow[b]{2}{*}{ Sample } & \multirow[b]{2}{*}{$E_{0}[\mathrm{keV}]$} & \multicolumn{4}{|c|}{ coordination shell } & \multicolumn{4}{|c|}{ further shells } & \multirow[b]{2}{*}{$\Delta \mathrm{E}_{0}[\mathrm{eV}]$} & \multirow[b]{2}{*}{$\mathrm{X}_{\mathrm{res}}[\%]$} \\
\hline & & $\mathbf{C N}^{a}$ & & $\mathbf{R}[\mathbf{A}]^{b}$ & $\sigma^{2}\left[\AA^{2}\right]^{c}$ & $\mathrm{CN}$ & & $\mathbf{R}[\AA]$ & $\sigma^{2}\left[\AA^{2}\right]$ & & \\
\hline \multirow[t]{3}{*}{ Se(IV)CopMt'-30min } & 12.6541 & 2.7 & $\mathrm{Fe}$ & 2.40 & 0.0037 & 1.0 & $\mathrm{Se}$ & 3.39 & 0.0066 & 12.7 & 4.3 \\
\hline & & & & & & 5.3 & $\mathrm{Se}$ & 3.89 & 0.0100 & $\S$ & \\
\hline & & & & & & 2.4 & $\mathrm{Fe}$ & 4.11 & 0.0074 & & \\
\hline \multirow[t]{3}{*}{$\mathrm{Se}(\mathrm{VI}) \mathrm{CopMt}^{1}-30 \mathrm{~min}$} & 12.6540 & 2.8 & $\mathrm{Fe}$ & 2.40 & 0.0036 & 0.5 & $\mathrm{Se}$ & 3.38 & 0.0052 & 12.9 & 3.6 \\
\hline & & & & & & 6.1 & $\mathrm{Se}$ & 3.90 & 0.0100 & $\S$ & \\
\hline & & & & & & 2.6 & $\mathrm{Fe}$ & 4.13 & 0.0070 & & \\
\hline \multirow[t]{5}{*}{ Se(IV)CopMt ${ }^{1}-2 d$} & 12.6556 & $2^{f}$ & $\mathrm{Se}$ & 2.38 & 0.0015 & $4^{f}$ & $\mathrm{Se}$ & 3.38 & 0.0047 & 10.6 & 3.8 \\
\hline & & & & & & $2^{f}$ & $\mathrm{Se}$ & 3.74 & 0.0034 & & \\
\hline & & & & & & $6^{f}$ & $\mathrm{Se}$ & 4.32 & 0.0058 & & \\
\hline & & & & & & $4^{f}$ & $\mathrm{Se}$ & 4.46 & 0.0046 & & \\
\hline & & & & & & $4^{f}$ & $\mathrm{Se}$ & 4.94 & 0.0048 & & \\
\hline \multirow[t]{5}{*}{$\mathrm{Se}(\mathrm{VI}) \mathrm{CopMt}^{1}-2 \mathrm{~d}$} & 12.6556 & $2^{f}$ & $\mathrm{Se}$ & 2.38 & 0.0015 & $4^{f}$ & $\mathrm{Se}$ & 3.38 & 0.0046 & 10.9 & 4.2 \\
\hline & & & & & & $2^{f}$ & $\mathrm{Se}$ & 3.74 & 0.0036 & & \\
\hline & & & & & & $6^{f}$ & $\mathrm{Se}$ & 4.31 & 0.0061 & & \\
\hline & & & & & & $4^{f}$ & $\mathrm{Se}$ & 4.45 & 0.0049 & & \\
\hline & & & & & & $4^{f}$ & $\mathrm{Se}$ & 4.94 & 0.0050 & & \\
\hline \multirow{6}{*}{$\begin{array}{l}\text { FeSe }^{*} \\
\text { (tetragonal P 4/n m m) }\end{array}$} & 12.6544 & $4^{f}$ & $\mathrm{Fe}$ & 2.38 & 0.0019 & $8^{f}$ & $\mathrm{Se}$ & 3.71 & 0.0070 & 4.7 & 7.3 \\
\hline & & & & $(2.37)$ & & & & 6-3.77) & & & \\
\hline & & & & & & $4^{f}$ & $\mathrm{Se}$ & 3.95 & 0.0030 & & \\
\hline & & & & & & & & (3.91) & & & \\
\hline & & & & & & $12^{f}$ & $\mathrm{Fe}$ & 4.44 & 0.0047 & & \\
\hline & & & & & & & $(4$. & $5-4.50)$ & & & \\
\hline \multirow{10}{*}{$\begin{array}{l}\text { gray selenium * } \\
\text { (trigonal } P 3_{1} 21 \text { ) }\end{array}$} & 12.6561 & $2^{f}$ & $\mathrm{Se}$ & 2.39 & 0.0028 & $4^{f}$ & $\mathrm{Se}$ & 3.38 & 0.0066 & 8.0 & 5.1 \\
\hline & & & & $(2.37)$ & & & & $(3.38)$ & & & \\
\hline & & & & & & $2^{f}$ & $\mathrm{Se}$ & 3.74 & 0.0048 & & \\
\hline & & & & & & & & $(3.74)$ & & & \\
\hline & & & & & & $6^{f}$ & $\mathrm{Se}$ & 4.30 & 0.0070 & & \\
\hline & & & & & & & & $(4.30)$ & & & \\
\hline & & & & & & $4^{f}$ & $\mathrm{Se}$ & 4.45 & 0.0052 & & \\
\hline & & & & & & & & $(4.45)$ & & & \\
\hline & & & & & & $4^{f}$ & $\mathrm{Se}$ & 4.94 & 0.0059 & & \\
\hline & & & & & & & & $(4.94)$ & & & \\
\hline
\end{tabular}

${ }^{\mathrm{a}} \mathrm{CN}$ : coordination number, error $\pm 25 \%$. ${ }^{\mathrm{b}} \mathrm{R}$ : Radial distance, error $\pm 0.01 \AA \AA^{\mathrm{c}} \sigma^{2}$ : Debye-Waller factor, error $\pm 0.0005 \AA^{2}$.

${ }^{f}$ fixed CN. ${ }^{\S}$ Upper $\sigma^{2}$ limit reached. "X" $c(S e)_{0}=" X " \cdot 10^{-3} \mathrm{~mol} / \mathrm{L}$.

* Data of references from Scheinost and Charlet ${ }^{18}$. Crystallographic values are given for comparison (in brackets).

For the $\mathrm{Se}(-\mathrm{II})$-bearing samples, the $\mathrm{k}^{3}$-weighted $\chi$ spectra were fit with a FEFF 8.2 file generated with the crystallographic structure of tetragonal iron(II) selenide (FeSe, CIF 26889; 
SI Table A.1). The EXAFS FT magnitude of these samples is dominated by a strong peak at $2.1 \AA$ (uncorrected for phase shift). A fit of this peak with a single scattering Se-Fe path lead to iron coordination numbers $(\mathrm{CN})$ of $2.7-2.8$ and to an atomic distance of $2.40 \AA$. The use of a Se-Se path, however, led to poor results. In case of the structural features in the EXAFS FT range between 3.1 - $3.5 \AA$ (uncorrected for phase shift), three individual single scattering Se-Fe and Se-Se paths had to be used to achieve a good fitting. This resulted in further shells of approximately $1 \mathrm{Se}$ atom at $3.39 \AA, 5-6 \mathrm{Se}$ atoms at $3.90 \AA$ and $2-3 \mathrm{Fe}$ atoms at $4.12 \AA$ (Table 2). A comparison with the known crystal structures of the iron selenides dzharkenite, ferroselite, achavalite, tetragonal $\mathrm{FeSe}, \mathrm{Fe}_{3} \mathrm{Se}_{4}$ or $\mathrm{Fe}_{7} \mathrm{Se}_{8}{ }^{29}$ demonstrates that none of these minerals match the observed atomic distances of the Se(-II) species within the reduced samples. The highest similarity shows tetragonal FeSe, which is characterized by a Fe coordination shell at $2.37 \AA$ and neighboring Se atoms in a distance of $3.91 \AA$. However, while unlike tetragonal FeSe, the reduced samples show no Se shell at approximately $3.77 \AA$, the documented Se and Fe shells at $3.38 \AA$ and $4.12 \AA$, respectively, are missing in case of tetragonal FeSe ${ }^{18}$.

The general observation that the structure of the selenium reduction product, which resulted from an interaction with reduced iron within the first minutes of the coprecipitation process, shows similarities with tetragonal FeSe was also observed in EXAFS studies by other authors $18,24,29,52$. Like in our study, the EXAFS fit of reduction products resulted in an Fe coordination shell at distances of $2.34-2.42 \AA$ and Se neighbors at $3.87-4.02 \AA \AA^{24,29,52}$. Moreover, some of these authors also observed additional Se and Fe shells similar to the observed Se shell at $3.38 \AA$ 18,52 or Fe shell at $4.12 \AA^{29}$, which are missing in the case of tetragonal FeSe. In addition, all EXAFS results have in common that the coordination numbers of the Fe and Se shells are much smaller than the ones of crystalline iron selenide minerals. This suggests that the reductive precipitation of selenium oxyanions leads to the formation of an iron selenide phase [FeSe] with particle sizes in the nanometer range 18,24,29,52. Even though these FeSe nanoparticles are characterized by a short-range structure, their binding structure is different from that of macrocrystalline FeSe minerals like achavalite or tetragonal FeSe. The theory of the formation of nanoparticulate FeSe is also strongly supported by the TEM results, providing the direct evidence that the FeSe particles are smaller than $100 \mathrm{~nm}$ (Fig. 5). Furthermore, the presence of poorly crystalline FeSe nanoparticles would explain why the FeSe phase could not be detected by XRD.

The fit of $\chi$ spectra of the Se(0)-bearing samples was performed with a FEFF 8.2 file generated with the crystallographic structure of gray trigonal Se (CIF 22251; SI Table A.1). As the ITFA 
as well as the XRD results have already shown that selenium is most likely present as crystalline gray Se in these samples, we used the first 6 single scattering Se-Se paths of this selenium reference with fixed coordination numbers for the fitting (Table 2). The perfect fit and the corresponding interatomic Se distances clearly show that the selenium species in these samples is indeed trigonal, gray Se.

That reduction of selenium oxyanions by reduced iron can result in the formation of gray elemental Se was also demonstrated in studies with iron(II) hydroxide ${ }^{20}$, siderite ${ }^{29}$, or $\mathrm{Fe}^{2+}$ sorbed on clay minerals ${ }^{30}$. Other publications, however, reported the formation of amorphous elemental Se. This includes studies related to the reduction potential of GR minerals ${ }^{21,23}$. In addition, Scheinost and Charlet ${ }^{18}$ showed that reduction of Se(IV) oxyanions by mackinawite led to the formation of nanoparticulate red Se.

\subsection{Conceptual model of the selenium retention during the magnetite formation}

The results of this study prove that the immobilization of selenium oxyanions during the aerial oxidation of an anoxic Fe-Se- $\mathrm{H}_{2} \mathrm{O}$ system, which involves the formation of magnetite, is due to two redox processes.

\subsubsection{Precipitation of FeSe}

The first redox process takes place under still reducing conditions in the early stage of the magnetite formation, where oxidation by atmospheric oxygen is not yet relevant. In this phase, dissolved selenium oxyanions interact with primarily Fe(II)-rich precipitation products of the aquatic $\mathrm{Fe}^{2+}$ system. These products are mainly iron(II) hydroxide and GR, which represent the unstable precursor phases of the later formed magnetite. This interaction leads to a reduction of $\mathrm{Se}(\mathrm{IV})$ or $\mathrm{Se}(\mathrm{VI})$ to $\mathrm{Se}(-\mathrm{II})$ and causes the formation of nanoparticulate iron selenide [FeSe] phase. At the same time, the Fe(II)-rich phases transform to Fe(III)-rich minerals, with corresponding oxidation of $\mathrm{Fe}(\mathrm{II})$ to $\mathrm{Fe}$ (III) during reductive selenium precipitation (Fig. 8).

It is known that the reduction of dissolved selenium oxyanions by $\mathrm{Fe}$ (II) requires the presence of iron(II) mineral phases and reaction with their active mineral surfaces ${ }^{31}$. Although the presence of dissolved $\mathrm{Fe}^{2+}$ generally favors the selenium reduction process ${ }^{51}$, a reduction only by dissolved $\mathrm{Fe}^{2+}$ is not possible due to the difference in reduction potentials of the redox couples ${ }^{60}$. Responsible for the selenium reduction is most likely the interaction with iron(II) hydroxide and its subsequent oxidation to GR, since larger amounts of GR form only in the presence of dissolved selenium oxyanions but not in Se-free systems. Thus, only the reductive selenium precipitation by iron(II) hydroxide and the associated production of $\mathrm{Fe}(\mathrm{III})$ makes the 
formation of an iron(II,III) mineral like GR possible under the prevailing anoxic condition. Regarding the formation of $\mathrm{GR}\left(\mathrm{Cl}^{-}\right)$, the corresponding redox reaction would be:

$$
\begin{aligned}
& 28 \mathrm{Fe}^{\mathrm{II}}(\mathrm{OH})_{2}+\mathrm{SeO}_{4}^{2-}+8 \mathrm{Cl}^{-}+5 \mathrm{Fe}^{2+}+4 \mathrm{H}_{2} \mathrm{O} \rightarrow 8 \mathrm{Fe}_{3}^{I I} \mathrm{Fe}^{I I I}(\mathrm{OH})_{8} \mathrm{Cl}+\mathrm{FeSe} \\
& 21 \mathrm{Fe}^{\mathrm{II}}(\mathrm{OH})_{2}+\mathrm{SeO}_{3}^{2-}+6 \mathrm{Cl}^{-}+4 \mathrm{Fe}^{2+}+3 \mathrm{H}_{2} \mathrm{O} \rightarrow 6 \mathrm{Fe}_{3}^{I I} \mathrm{Fe}^{I I I}(\mathrm{OH})_{8} \mathrm{Cl}+\mathrm{FeSe}
\end{aligned}
$$

As can be seen from these equations, the quantity of available iron(II) hydroxide determines the total amount of immobilized selenite or selenate. Since the reduction of selenate to FeSe requires more $\mathrm{Fe}(\mathrm{II})$ than the reduction of selenite, the amount of reduced selenite is always higher at a specific $\mathrm{Se} / \mathrm{Fe}(\mathrm{II})$ ratio. However, the amount of immobilized selenium also depends on the reduction kinetics, whereby particularly the reduction step of $\operatorname{Se}(\mathrm{VI})$ to $\mathrm{Se}(\mathrm{VI})$ is kinetically hindered ${ }^{2,61}$.

Concerning the question why the reduction of selenium oxyanions sometimes causes the formation of $\mathrm{FeSe}$ and sometimes of elemental Se, Scheinost et al. ${ }^{29}$ postulated a theory according to which the type of precipitation product is linked to the reduction kinetics. While formation of iron selenides is only possible in case of fast reduction kinetics, a slow selenium reduction favors the precipitation of elemental Se. In general, the reduction kinetics is directly related to the particle sizes and morphology of the interacting Fe(II)-bearing mineral phases. A fast selenium reduction is therefore only possible in case of relatively small particles with high specific surface areas ${ }^{18,29}$. Since the selenium reduction process mainly takes place within the first 30 minutes and through the interaction with iron(II) hydroxide and GR, which are both characterized by small particle sizes and/or high specific surface areas, the results of this study are consistent with the theory that the reduction kinetics defines the selenium precipitation product.

Moreover, Kang et $a l^{62}$ found out that the total amount of selenium oxyanions plays an important role in this context. This is due to the fact that the remaining non-reduced selenium oxyanions prevent the precipitation of FeSe and support the formation of elemental Se:

$$
\begin{aligned}
& \mathrm{SeO}_{3}^{2-}+2 \mathrm{FeSe}+6 \mathrm{H}^{+} \rightarrow 3 \mathrm{Se}^{0}+2 \mathrm{Fe}^{2+}+3 \mathrm{H}_{2} \mathrm{O} \\
& \mathrm{SeO}_{4}^{2-}+3 \mathrm{FeSe}+8 \mathrm{H}^{+} \rightarrow 4 \mathrm{Se}^{0}+3 \mathrm{Fe}^{2+}+4 \mathrm{H}_{2} \mathrm{O}
\end{aligned}
$$

However, because of the alkaline $\mathrm{pH}$ as well as the relatively large amount of iron(II) mineral phases, resulting in a small amount of remaining selenium oxyanions, one can assume that this reaction is prevented in our studies. 


\subsubsection{Transformation of FeSe into elemental selenium}

The second important selenium redox reaction takes place during the progressive oxidation of the aquatic system due to the contact with atmospheric oxygen. This process leads to further oxidation of $\mathrm{Fe}(\mathrm{II})$ to $\mathrm{Fe}(\mathrm{III})$ and thereby to the complete transformation of iron(II) hydroxide and GR into magnetite. Besides that, however, the entry of oxygen also causes the oxidation of $\mathrm{Se}(-\mathrm{II})$ to $\mathrm{Se}(0)$. As a consequence, the nanoparticulate FeSe oxidizes to gray elemental Se that occurs in form of euhedral crystals with sizes of $1-2 \mu \mathrm{m}$ within the magnetite matrix (Fig. 8). The oxidation of FeSe in elemental Se can generally be described by the following two-part dissolution-precipitation reaction:

$$
\begin{gathered}
\mathrm{FeSe}+\mathrm{H}^{+} \rightarrow \mathrm{Fe}^{2+}+\mathrm{HSe}^{-} \\
\mathrm{HSe}^{-}+0.5 \mathrm{O}_{2}+\mathrm{H}^{+} \rightarrow \mathrm{Se}^{0}+\mathrm{H}_{2} \mathrm{O}
\end{gathered}
$$

As can be derived from this reaction, formation of microcrystalline gray Se from nanoparticulate FeSe should not be possible when the introduced $\mathrm{O}_{2}$ reacts primarily with the FeSe phases. Otherwise it is hard to explain how the $\mathrm{HSe}^{-}$remains stable long enough to form Se particles of larger sizes. However, if the entry of $\mathrm{O}_{2}$ mainly causes the oxidation of the iron hydroxides, this would result in a buffering of the system and in the preservation of the initial anoxic conditions. Kurokawa and Senna ${ }^{63}$ reported a self-stabilization effect of GR against aerial oxidation by adsorption of dissolved $\mathrm{Fe}^{2+}$. This oxidation process would then inevitably lead to a consumption of $\mathrm{Fe}^{2+}$, which in turn would cause the dissolution of the most unstable $\mathrm{Fe}(\mathrm{II})$-containing mineral phases. In this context, dissolution of the nanoparticulate FeSe comes into questions, since FeSe has a relatively high solubility compared to other iron selenides or iron(II) hydroxides ${ }^{62}$. Furthermore, it is known that the solubility of nanoparticulate phases can be significantly higher than for crystalline particles of larger sizes ${ }^{5}$. Due to the buffering effect, the hereby formed $\mathrm{HSe}^{-}$species would be stable for a longer time. This would allow a more controlled and slower Se(-II) oxidation and thus the formation of elemental Se with larger particle sizes.

It must also be noted that elemental Se is still the dominant selenium phase at the end of the coprecipitation process, even though $\mathrm{Se}(0)$ is not the thermodynamically favored oxidation state under alkaline, oxic conditions. This is probably influenced by the relatively large size of the elemental Se crystals that inhibits further oxidation of $\operatorname{Se}(0)$. Since the progressive oxidation is not accompanied by remobilization of selenium and there is also no indication of a further selenium oxidation, the stability of the selenium immobilization seems to be mainly determined by the previous transformation of unstable FeSe into elemental Se. Interestingly, the whole 
selenium retention mechanism is also not affected by the nature of the final iron oxide precipitation product (Fig. A.4). Dissolved selenium oxyanions are initially reduced to FeSe and then oxidized to gray elemental Se, regardless of whether the oxidation of iron(II) hydroxide and GR leads to the formation of magnetite or iron(III) oxyhydroxides like goethite and lepidocrocite.

\section{Conclusion}

The results of this study demonstrated that the formation pathway of magnetite is more crucial for the immobilization of dissolved selenium oxyanions than the interaction processes after the completed mineral formation. Key factor is the contact and interaction of selenium oxyanions with metastable $\mathrm{Fe}(\mathrm{II})$-rich intermediates, which causes a reductive selenium precipitation and defines the retention capacity. Also of great importance are the prevailing hydrochemical conditions, including $\mathrm{pH}$ and redox, since those parameters primarily determine the iron oxide formation and transformation pathway as well as the nature and stability of the selenium precipitation products. In case of the here investigated conditions, this behavior led to the initial reduction of $\mathrm{Se}(\mathrm{IV})$ or $\mathrm{Se}(\mathrm{VI})$ oxyanions to $\mathrm{FeSe}$, which was afterwards oxidized to gray elemental Se during the progressive aerial oxidation process.

Regarding the behavior of selenium in the geosphere, the study showed that reductive selenium precipitation represents an efficient and comparatively durable mechanism to immobilize dissolved selenium oxyanions. Processes like these should be considered in safety assessments of HLW disposal sites, as they may affect the migration of the radionuclide ${ }^{79} \mathrm{Se}$ (interaction of ${ }^{79} \mathrm{Se}$ with secondary iron oxides in the near-field). Moreover, one could imagine that this mechanisms are used actively to reduce the appearance of mobile selenium species. An intended manipulation of the redox-dependent selenium solubility due to the entry of reduced iron could, for example, be applied in the treatment of selenium contaminated wastewaters.

\section{Conflicts of interest}

There are no conflicts of interest to declare.

\section{Acknowledgements}

This work is part of the IMMORAD project, funded by the German Federal Ministry for Education and Research (BMBF) under grant No. 02NUK019B. Additional financial support was provided by the Graduate School for Climate and Environment (GRACE) at KIT. The authors would like to thank Dr. Arne Jansen and Volker Zibat for S/TEM and SEM analysis, 
Dr. Peter Weidler for BET determination and Dr. Jörg-Detlef Eckhardt for assistance with XRD analysis. We also thank Dr. Utz Kramar and Claudia Mößner for their help during XRF and ICP-MS analysis. The ESRF and the team of the Rossendorf Beamline (BM 20) are gratefully acknowledged for the provision of beam time and their support during the XAS measurements.

\section{References}

1 M. Lenz and P. N. L. Lens, Sci. Total Environ., 2009, 407, 3620-3633.

2 P. De Cannière, A. Maes, S. Williams, C. Bruggeman, T. Beauwens, N. Maes and M. Cowper, Behaviour of Selenium in Boom Clay. External Report of the Belgian Nuclear Research Centre, SCK•CEN-ER-120, Mol, BEL, 2010.

3 G. Jörg, R. Bühnemann, S. Hollas, N. Kivel, K. Kossert, S. Van Winckel and C. Lierse v. Gostomski, Appl. Radiat. Isot., 2010, 68, 2339-2351.

4 B. Grambow, J. Contam. Hydrol., 2008, 102, 180-186.

5 A. Fernández-Martínez and L. Charlet, Rev. Environ. Sci. Biotechnol., 2009, 8, 81-110.

6 F. Séby, M. Potin-Gautier, E. Giffaut, G. Borge and O. F. X. Donard, Chem. Geol., 2001, 171, 173-194.

$7 \quad$ K. S. Dhillon and S. K. Dhillon, Adv. Agron., 2003, 79, 119-184.

8 L. H. E. Winkel, B. Vriens, G. D. Jones, L. S. Schneider, E. Pilon-Smits and G. S. Bañuelos, Nutrients, 2015, 7, 4199-4239.

9 A. K. Nothstein, E. Eiche, M. Riemann, P. Nick, L. H. E. Winkel, J. Göttlicher, R. Steininger, R. Brendel, M. Von Brasch, G. Konrad and T. Neumann, PLoS One, , DOI:10.1371/journal.pone.0152081.

10 E. Curti, A. Froideval-Zumbiehl, I. Günther-Leopold, M. Martin, A. Bullemer, H. Linder, C. N. Borca and D. Grolimund, J. Nucl. Mater., 2014, 453, 98-106.

11 E. Curti, A. Puranen, D. Grolimund, D. Jädernas, D. Sheptyakov and A. Mesbah, Environ. Sci. Process. Impacts, 2015, 17, 1760-1768.

12 P. A. Bingham, A. J. Connelly, N. J. Cassingham and N. C. Hyatt, J. Non. Cryst. Solids, 2011, 357, 2726-2734.

13 E. Smailos, W. Schwarzkopf, B. Kienzler and R. Köster, MRS Proc., 1992, 257, 299-406.

14 W. Miller, R. Alexander, N. Chapman, J. C. McKinley and J. A. T. Smellie, Geological Disposal of Radioactive Wastes and Natural Analogues, Elsevier Science, 2000.

15 P. Wersin, L. H. Johnson, B. Schwyn, U. Berner and E. Curti, Redox Conditions in the Near Field of a Repository for SF/HLW and ILW in Opalinus Clay. NAGRA Technical Report 02-13, Wettingen, CH, 2003.

16 N. R. Smart, A. P. Rance and L. O. Werme, J. Nucl. Mater., 2008, 379, 97-104.

17 R. M. Cornell and U. Schwertmann, The iron oxydes: Structure, Properties, Reactions, Occurences and Uses, Wiley-VCH, Weinheim, Germany, 2nd edn., 2003.

18 A. C. Scheinost and L. Charlet, Environ. Sci. Technol., 2008, 42, 1984-1989.

19 A. P. Murphy, Ind. Eng. Chem. Res., 1988, 27, 187-191.

20 R. A. Zingaro, D. C. Dufner, A. P. Murphy and C. D. Moody, Environ. Int., 1997, 23, 299-304.

21 S. C. B. Myneni, T. K. Tokunaga and G. E. Brown Jr., Science., 1997, 278, 1106-1109.

22 T. M. Johnson and T. D. Bullen, Geochim. Cosmochim. Acta, 2003, 67, 413-419. 
A. M. Scheidegger, D. Grolimund, D. Cui, J. Devoy, K. Spahiu, P. Wersin, I. Bonhoure and M. Janousch, J. Phys. IV, 2003, 104, 417-420.

J. T. Olegario, N. Yee, M. Miller, J. Sczepaniak and B. Manning, J. Nanoparticle Res., 2010, 12, 2057-2068.

I.-H. Yoon, K.-W. Kim, S. Bang and M. G. Kim, Appl. Catal. B Environ., 2011, 104, 185-192.

L. Liang, W. Yang, X. Guan, J. Li, Z. Xu, J. Wu, Y. Huang and X. Zhang, Water Res., 2013, 47, $5846-5855$.

L. Ling, B. Pan and W. Zhang, Water Res., 2015, 71, 274-281.

C. Bruggeman, A. Maes, J. Vancluysen and P. Vandemussele, Environ. Pollut., 2005, 137, 209 21.

A. C. Scheinost, R. Kirsch, D. Banerjee, A. Fernandez-Martinez, H. Zaenker, H. Funke and L. Charlet, J. Contam. Hydrol., 2008, 102, 228-245.

L. Charlet, A. C. Scheinost, C. Tournassat, J. M. Greneche, A. Géhin, A. Fernández-Martínez, S. Coudert, D. Tisserand and J. Brendle, Geochim. Cosmochim. Acta, 2007, 71, 5731-5749.

Y.-W. Chen, H.-Y. T. Truong and N. Belzile, Chemosphere, 2009, 74, 1079-1084.

N. Kämpf, A. C. Scheinost and D. G. Schulze, in Handbook of Soil Sciences: Properties and Processes, eds. P. M. Huang, Y. Li and M. E. Sumner, CRC Press, Boca Raton, USA, 2nd edn., 2011, p. 1442.

H.-P. Blume, G. W. Brümmer, H. Fleige, R. Horn, E. Kandeler, I. Kögel-Knabner, R. Kretzschmar, K. Stahr and B.-M. Wilke, Scheffer/Schachtschabel - Soil Science, Springer, Heidelberg, Germany, 16th edn., 2016.

34 N. Börsig, A. C. Scheinost, S. Shaw, D. Schild and T. Neumann, Geochim. Cosmochim. Acta, 2017, 206, 236-253.

35 P. C. M. Francisco, T. Sato, T. Otake, T. Kasama, S. Suzuki, H. Shiwaku and T. Yaita, Environ. Sci. Technol., , DOI:10.1021/acs.est.8b00462.

36 U. Schwertmann and R. M. Cornell, Iron oxides in the laboratory: Preparation and characterization, Wiley-VCH, Weinheim, Germany, 2nd edn., 2000.

T. Ressler, J. Synchrotron Radiat., 1998, 5, 118-122.

A. L. Ankudinov and J. J. Rehr, Phys. Rev. B, 1997, 56, 1712-1715.

A. Rossberg, T. Reich and G. Bernhard, Anal. Bioanal. Chem., 2003, 376, 631-638.

40 F. Huber, D. Schild, T. Vitova, J. Rothe, R. Kirsch and T. Schäfer, Geochim. Cosmochim. Acta, 2012, 96, 154-173.

J. Tang, M. Myers, K. a Bosnick and L. E. Brus, J. Phys. Chem. B, 2003, 107, 7501-7506.

R. L. Rebodos and P. J. Vikesland, Langmuir, 2010, 26, 16745-16753.

H. Drissi, P. Refait and J.-M. R. Génin, Hyperfine Interact., 1994, 90, 395-400.

P. Refait, M. Abdelmoula and J.-M. R. Génin, Corros. Sci., 1998, 40, 1547-1560.

U. Schwertmann and H. Fechter, Clay Miner., 1994, 29, 87-92.

O. P. Perez, Y. Umetsu and H. Sasaki, Hydrometallurgy, 1998, 50, 223-242. 
51 C. Tang, Y. H. Huang, H. Zeng and Z. Zhang, Water Res., 2014, 67, 166-174.

52 R. L. de A. Loyo, S. I. Nikitenko, A. C. Scheinost and M. Simonoff, Environ. Sci. Technol., 2008, 42, 2451-2456.

53 N. Jordan, C. Lomenech, N. Marmier, E. Giffaut and J.-J. Ehrhardt, J. Colloid Interface Sci., 2009, 329, 17-23.

54 T. Missana, U. Alonso, A. C. Scheinost, N. Granizo and M. García-Gutiérrez, Geochim. Cosmochim. Acta, 2009, 73, 6205-6217.

55 M. Rovira, J. Giménez, M. Martínez, X. Martínez-Lladó, J. de Pablo, V. Martí and L. Duro, J. Hazard. Mater., 2008, 150, 279-284.

56 K. Mitchell, R.-M. Couture, T. M. Johnson, P. R. D. Mason and P. Van Cappellen, Chem. Geol., 2013, 342, 21-28.

57 Y. Wang, G. Morin, G. Ona-Nguema, F. Juillot, G. Calas and G. E. Brown, Environ. Sci. Technol., 2011, 45, 7258-7266.

58 L. Legrand, L. Mazerolles and A. Chaussé, Geochim. Cosmochim. Acta, 2004, 68, 3497-3507.

59 J.-M. R. Génin, C. Ruby, A. Géhin and P. Refait, Comptes Rendus Geosci., 2006, 338, 433-446.

60 S. Chakraborty, F. Bardelli and L. Charlet, Environ. Sci. Technol., 2010, 44, 1288-1294.

61 F. Séby, M. Potin-Gautier, E. Giffaut and O. F. X. Donard, Analusis, 1998, 26, 193-198.

62 M. Kang, B. Ma, F. Bardelli, F. Chen, C. Liu, Z. Zheng, S. Wu and L. Charlet, J. Hazard. Mater., 2013, 248-249, 20-28.

63 H. Kurokawa and M. Senna, Powder Technol., 1999, 71-79. 
a)

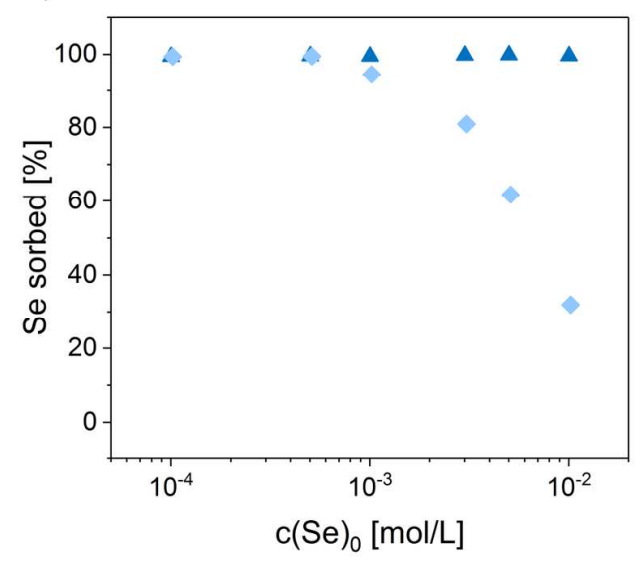

b)

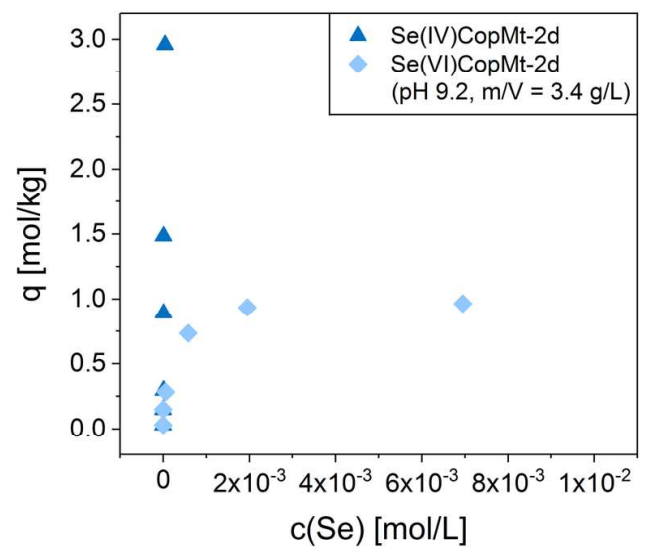

Retention of selenite [Se(IV)] and selenate [Se(VI)] during the coprecipitation (Cop) with magnetite (Mt). (a) Selenium sorption as a function of the initial Se concentration, (b) Selenium uptake as a function of the Se equilibrium concentration.

$82 \times 39 \mathrm{~mm}(600 \times 600 \mathrm{DPI})$ 


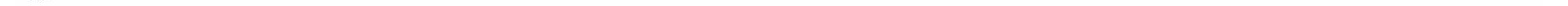




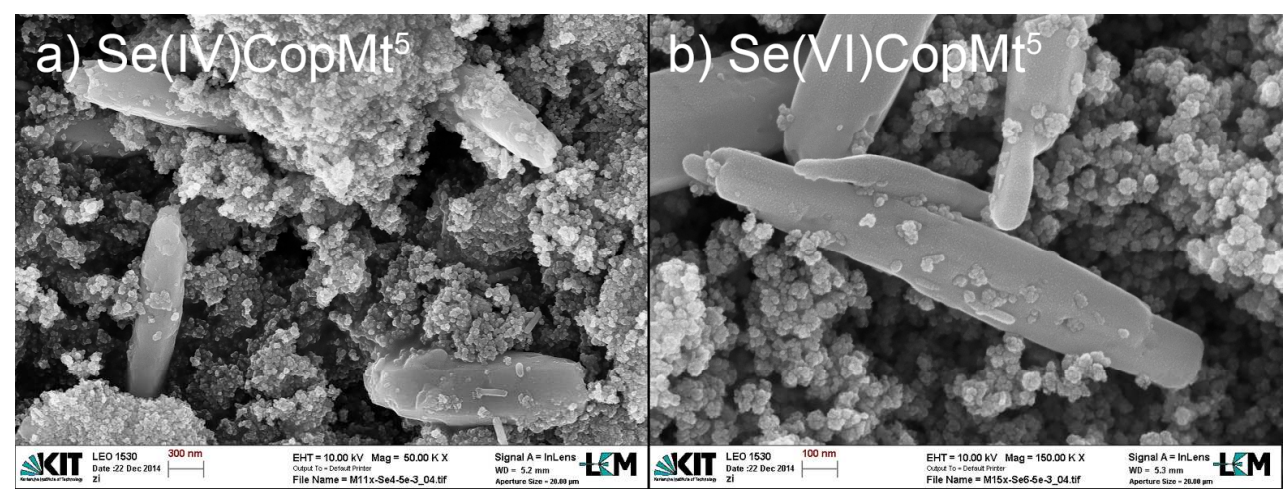

SEM images of coprecipitation products consisting of elemental Se crystals in a matrix of magnetite. (a) Selenite-magnetite coprecipitation; (b) Selenate-magnetite coprecipitation. c(Se)0 = 5.10-3 mol/L.

$173 \times 64 \mathrm{~mm}(300 \times 300 \mathrm{DPI})$ 


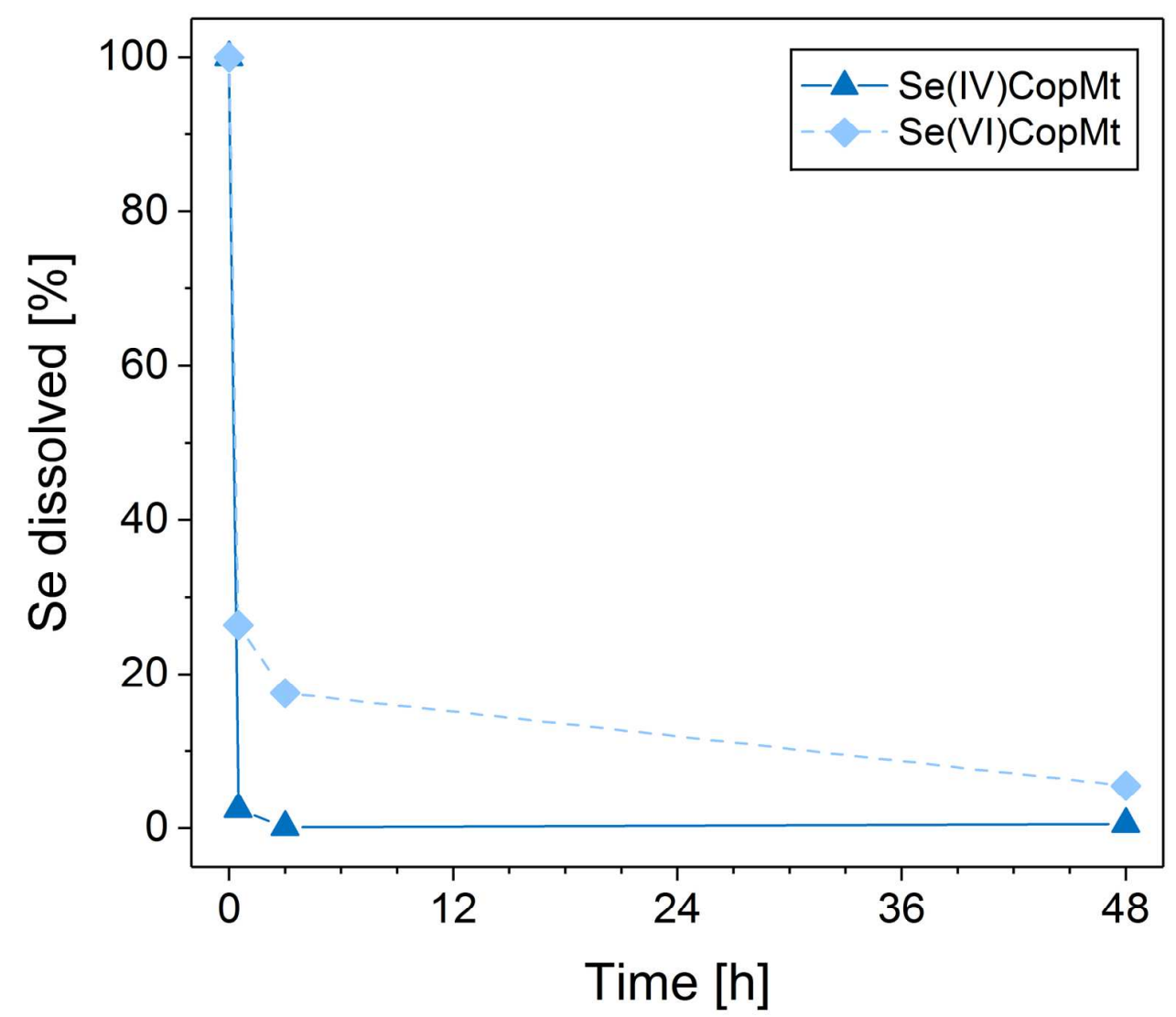

Evolution of the selenite [Se(IV)] or selenate [Se(VI)] concentration during the coprecipitation process.

$83 \times 72 \mathrm{~mm}(600 \times 600 \mathrm{DPI})$ 

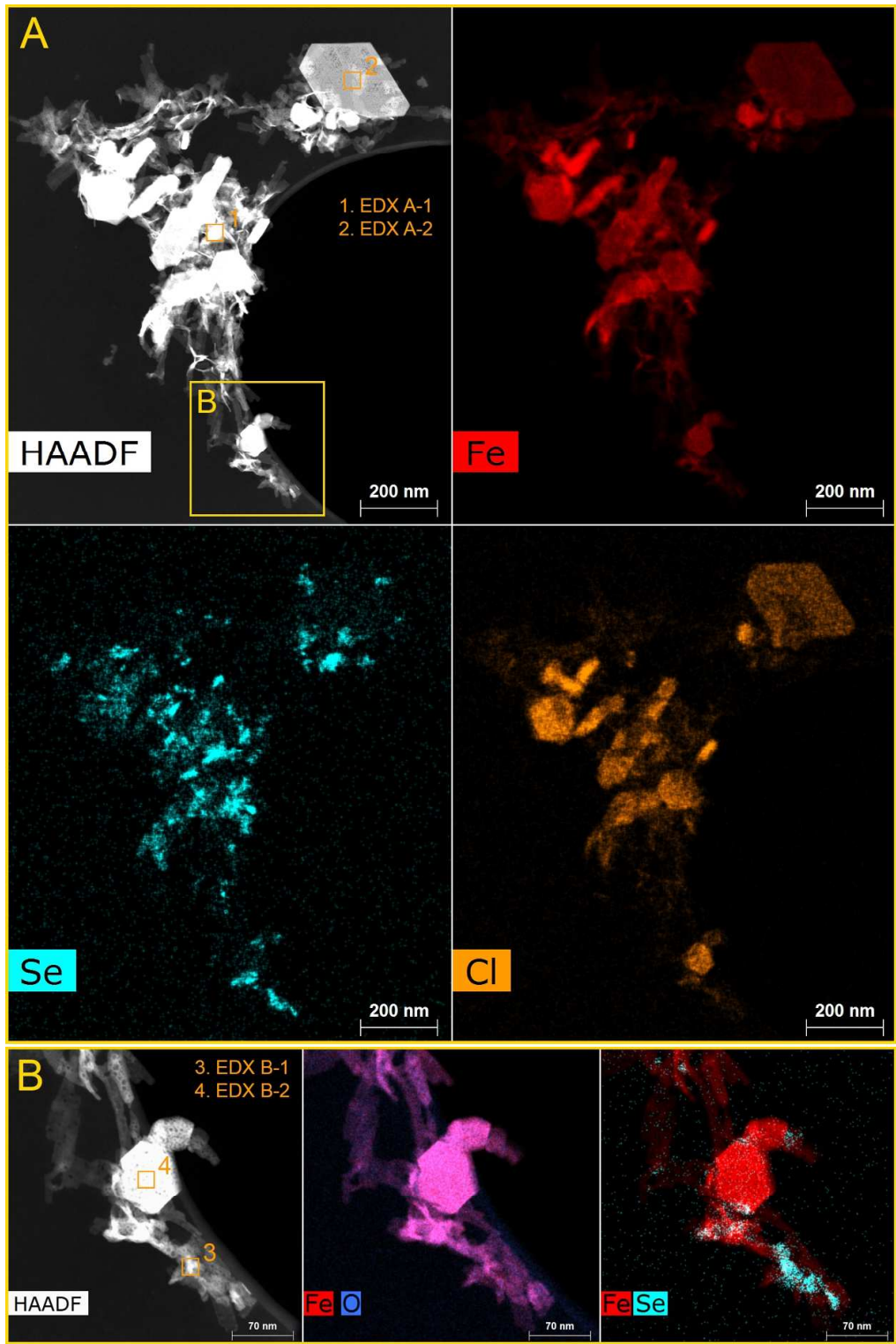

HAADF images and elemental mappings of a Selenite-magnetite coprecipitation product after a reaction time of 30 min. EDX spectra of the marked spots are shown in Fig. A.8. 

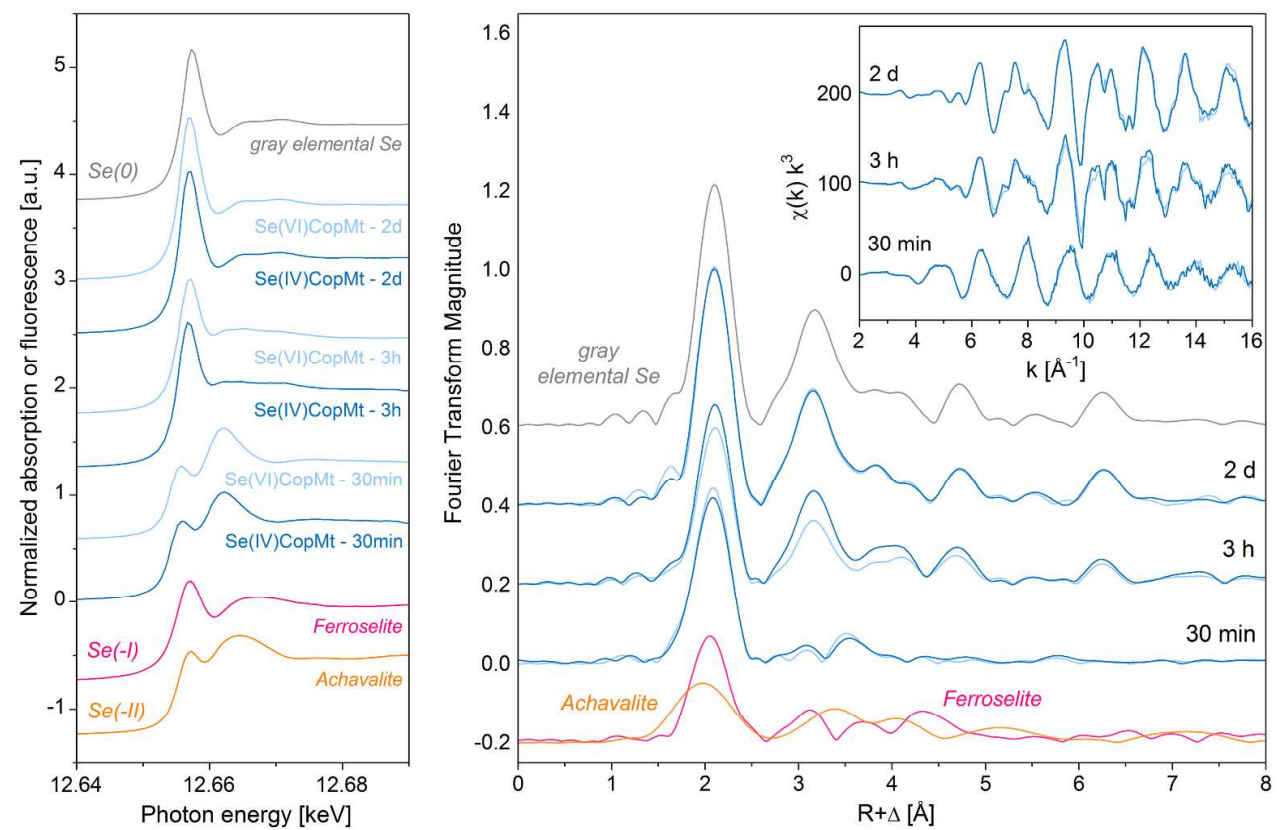

Se K-edge XANES and EXAFS spectra of Selenite-magnetite and Selenate-magnetite coprecipitation products of different reaction times and various selenium references.

$125 \times 81 \mathrm{~mm}(600 \times 600 \mathrm{DPI})$ 
Fourier transform magnitude
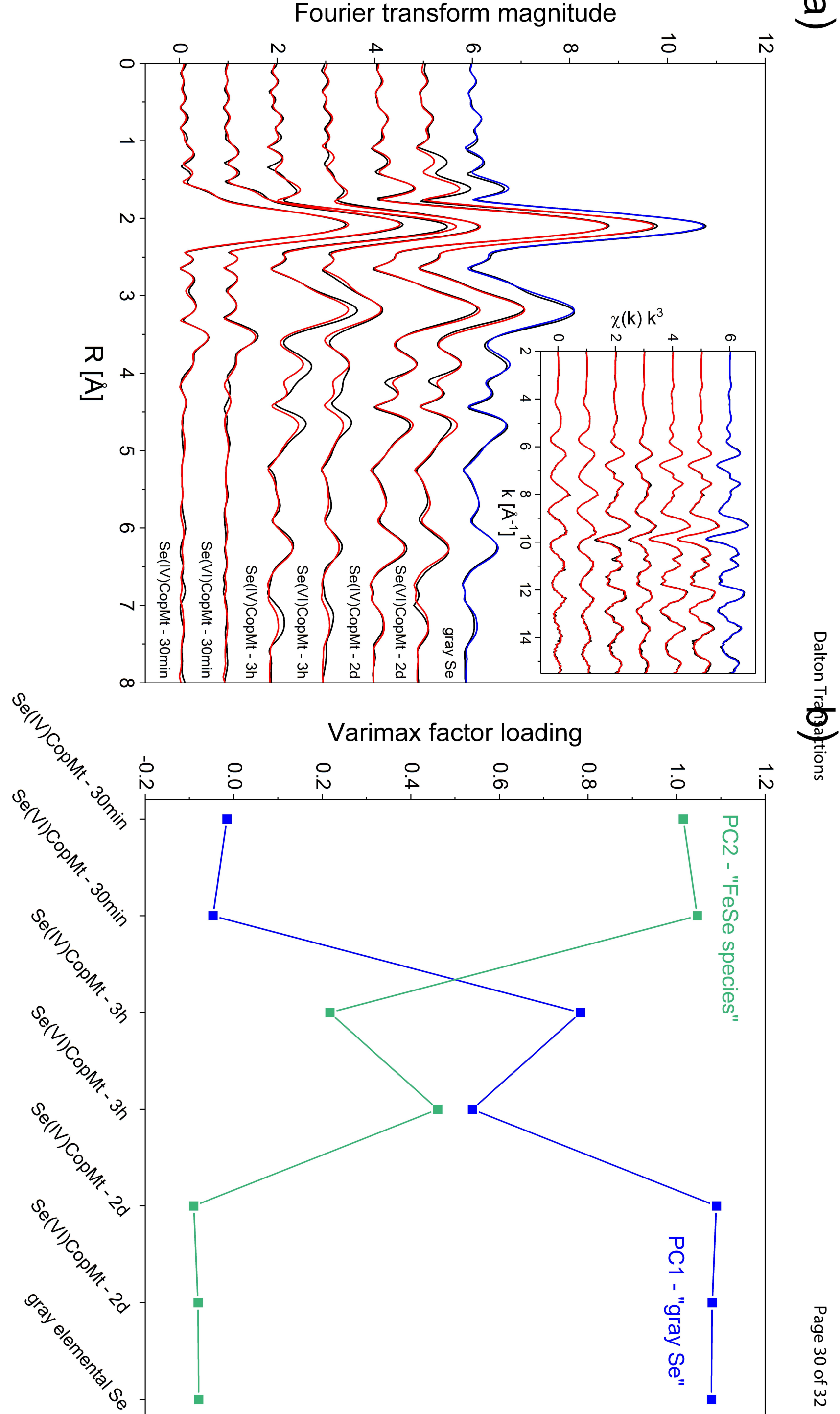


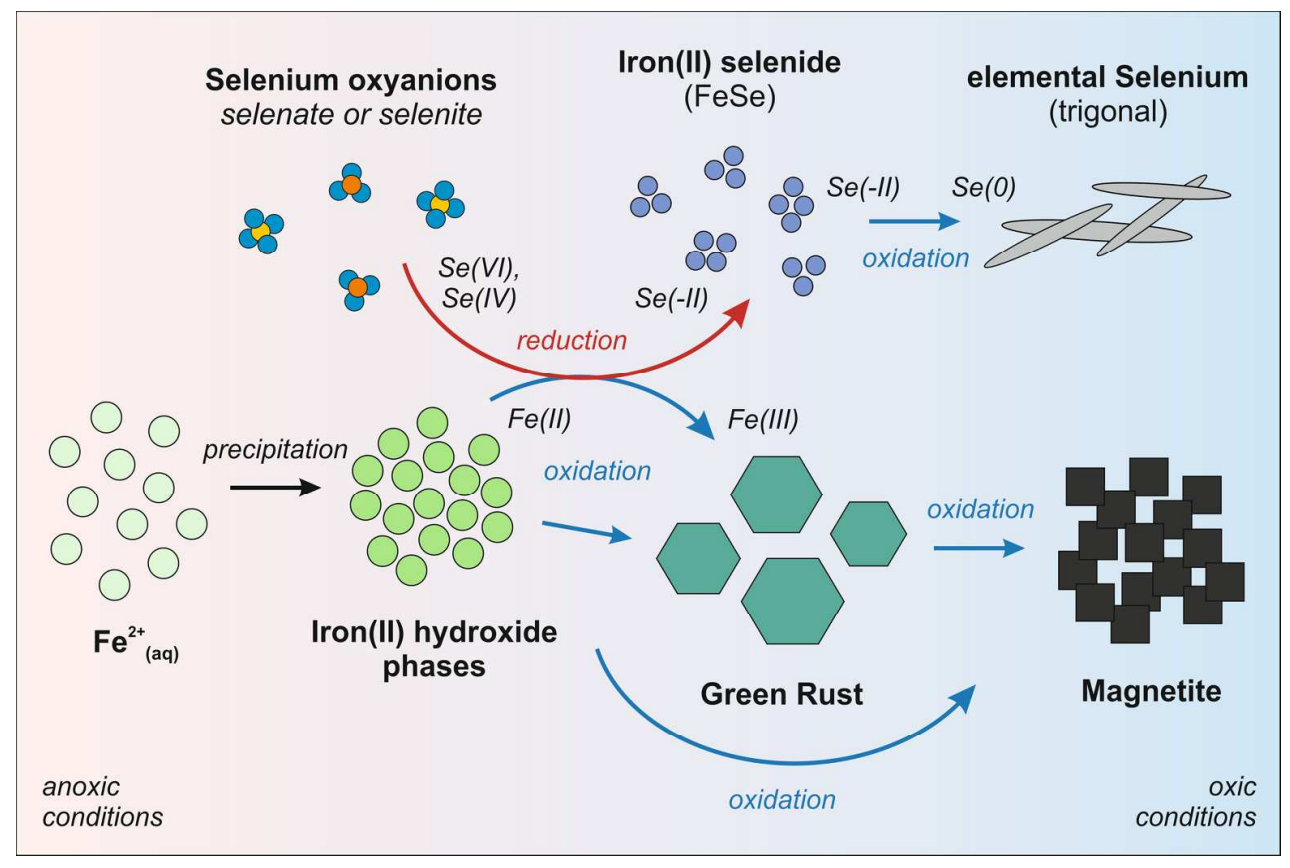

Schematic representation of the retention of selenium oxyanions during the formation of magnetite.

$177 \times 118 \mathrm{~mm}(300 \times 300 \mathrm{DPI})$ 
Email: nicolas.boersig@kit.edu

\section{Table of Contents entry (DT-ART-05-2018-001799)}

Graphical and textual abstract for the contents pages

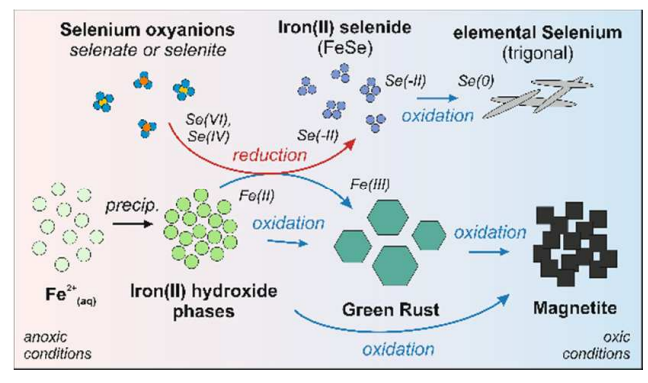

This article provides new insights into selenite and selenate reduction chemistry and immobilization mechanisms in the presence of $\mathrm{Fe}(\mathrm{II})$ and $\mathrm{O}_{2}$ 